\title{
CORPOGRAFÍAS JUVENILES Y GENERACIONES EN CONTEXTOS DE INCERTIDUMBRE: SUBJETIVACIÓN, DIVERGENCIA \\ E INDUSTRIA DE LA FELICIDAD \\ EN EL CHILE ACTUAL ${ }^{1}$
}

\author{
RODRIGO GANTER SOLÍS* \\ DANIELA CARrasco SAN MARTíN** \\ PABlo PinTo VAlenZUela***
}

\begin{abstract}
RESUMEN
El artículo constituye parte del trabajo de discusión de resultados inscrito en una iniciativa Fondecyt, sobre relatos y prácticas de lo corporal en jóvenes urbanos en Chile, desarrollado entre los años 2015 y 2017. El objetivo del texto es analizar los principales significados, hábitos y cuidados que las juventudes desarrollan en torno a la experiencia corporal y la imagen personal; identificando imaginarios, procesos de subjetivación y agentes sociales que alimentan, regulan y tensionan dichas dinámicas; en un escenario social de marcada incertidumbre y malestar social, particularmente visible en las nuevas generaciones. La metodología utilizada fue de carácter biográfico e incluyó 40 relatos de vida de jóvenes de diversos mundos sociales, segmentos socioeconómicos, intereses y estilos de vida, en las ciudades de Concepción y Santiago. El trabajo propone una tipología de experiencias corporales y una corpografía que sintetiza las visiones de lo corporal expresadas al interior de cada tipología, mediante la cual se pueden observar algunas tensiones y alternativas presentes en diversas generaciones y mundos juveniles.
\end{abstract}

PALABRAS CLAVE: JUVENTUDES, INCERTIDUMBRE, EXPERIENCIA CORPORAL, INDUSTRIA DEL

${ }^{1}$ Este artículo forma parte de la presentación y difusión de resultados del Proyecto Fondecyt $\mathrm{n}^{\circ}$ 1114086, Relatos y Prácticas de lo Corporal en Jóvenes Urbanos de Concepción y Santiago (2015-2017). Agradecemos a todxs lxs jóvenes que participaron del estudio regalándonos su tiempo, sus saberes y sus valiosas historias de vida, y a quienes nos hicieron llegar sus observaciones e indicaciones en materia de resultados, lo que sin duda nos ayudó a calibrar mejor nuestras interpretaciones. Vaya un agradecimiento especial a Ángela en "representación" de todxs ellxs.

* Sociólogo, Doctor en Estudios Urbanos, Universidad Católica de Chile. Investigador responsable Proyecto Fondecyt $\mathrm{n}^{\circ}$ 1114086. Profesor e investigador del Depto. de Sociología, Universidad de Concepción - Chile. rganter@udec.cl.

** Socióloga, Master in Sociology, University of Sheffield, Reino Unido. Co-investigadora en el proyecto Fondecyt $n^{\circ}$ 1114086. Investigadora, Dirección de Equidad de Género y Diversidad, Universidad de Concepción -Chile. mariadcarrasco@udec.cl

*** Sociólogo, Magister en Investigación Social y Desarrollo, Universidad de Concepción Chile. Asistente de investigación proyecto Fondecyt n 1114086. ppintov@udec.cl 
CUIDADO PERSONAL, SUBJETIVACIÓN GENERACIONAL

\title{
CORPOGRAFIAS JUVENIS E GERACIONAIS EM CONTEXTOS DE INCERTEZA: SUBJETIVAÇÃO, DIVERGÊNCIA E INDÚSTRIA DA FELICIDADE NO CHILE ATUAL
}

\begin{abstract}
RESUMO
O artigo constitui parte do trabalho de discussão de resultados inscrito em uma iniciativa Fondecyt sobre relatos e práticas do corporal em jovens urbanos no Chile, desenvolvida entre os anos 2015 e 2017. O objetivo do texto é analisar os principais significados, hábitos e cuidados que as juventudes desenvolvem em torno da experiência corporal e da imagem pessoal; identificando imaginários, processos de subjetivação e agentes sociais que alimentam, regulam e tensionam essas dinâmicas; em um cenário social de evidente incerteza e mal-estar social, particularmente visível nas novas gerações. A metodologia utilizada foi de caráter biográfico e incluiu 40 relatos de vida de jovens de diferentes mundos sociais, estratos socioeconômicos, interesses e estilos de vida nas cidades de Concepción e Santiago. O trabalho propõe uma tipologia de experiências corporais e uma corpografia que sintetiza as visões do corporal expressadas dentro de cada tipologia, através da qual é possível observar algumas tensões e alternativas presentes em diferentes gerações e mundos juvenis.
\end{abstract}

\author{
PALAVRAS-CHAVE: JUVENTUDES, INCERTEZA, EXPERIÊNCIA CORPORAL, INDÚSTRIA DE \\ CUIDADOS PESSOAIS, SUBJETIVAÇÃO GERACIONAL
}

\author{
YOUTH BODYGRAPHIES AND GENERATIONS IN CONTEXTS OF UNCERTAINTY: \\ SUBJECTIVATION, DIVERGENCE AND HAPPINESS INDUSTRY IN CONTEMPORARY CHILE
}

\begin{abstract}
The article is part of the result discussion work in the context of a Fondecyt initiative on corporal practices and narratives in Chilean urban young individuals carried out between 2015 and 2017. The objective of the text is to analyze the main meanings, habits and care that youths develop towards their corporal experience and personal image, by means of identifying imaginaries, processes of subjectivation and social agents feeding, regulating and tensing these dynamics, in a social scenario of strong uncertainty and social discomfort particularly visible in younger generations. A biographical method was used, including 40 life stories of young individuals from diverse social contexts, socioeconomic strata, interests and lifestyles in the cities of Concepcion and Santiago. The work proposes a typology of corporal experiences, and a bodygraphy synthesizing the corporal-related visions expressed within each typology, allowing the observation of some tensions and alternatives in diverse generations and young worlds.
\end{abstract}




\section{KEYWORDS: YOUTHS - UNCERTAINTY - BODY EXPERIENCE - PERSONAL CARE INDUSTRY- GENERATIONAL SUBJECTIVATION}

\section{ConteXtos}

Inaugurado el siglo XXI, el informe PNUD (2002) para Chile hacía alusión a una de las tensiones más agobiantes que debían enfrentar las personas: la construcción de una imagen de sí mismos y un proyecto de vida satisfactorio en un contexto social de desestabilización de referentes tradicionales y de alta incertidumbre y precarizaciones biográficas. En ese escenario, el PNUD (2002) plantea el importante incremento (646\%) que tuvo en el país la importación de bienes de consumo estéticos (perfumes, aparatos de cuidado estéticos, etc.), aludiendo a una tendencia mediante la cual la biografía individual en el Chile actual está fuertemente orientada por una estetización del yo (Featherston, 1991), de su imagen en las redes sociales y de la propia vida cotidiana. Esto refuerza la idea de que, para muchos/as, el valor de un objeto ya no radica tanto en lo que es o lo que hace, sino en lo que significa (autorrealización) y comunica a otros. Lo anterior va marcando un cierto clima de época, que transforma los modos de ser, estar y moverse en el mundo. El régimen de visibilidad y el mercado de las apariencias son centrales para comprender estas mutaciones, junto con las actuales dinámicas de subjetivación y cultivo de sí. ${ }^{2}$

En esa misma línea, el informe PNUD-INJUV (2003) visualiza un conjunto de «mundos juveniles», en un contexto de profundas transformaciones culturales que generan variados desafíos y amenazas para las juventudes frente al cambio de siglo en Chile. Dichos mundos juveniles incluyen crecientes y diversas dinámicas de individuación juvenil, asociadas con trayectorias familiares, educacionales y laborales; expectativas de futuro y lógicas de gestión de sí, vinculadas con oportunidades y condiciones sociales de existencia altamente diversas y desiguales, en tanto expresión patente del Chile actual. Asimismo, el informe plantea que los proveedores de sentido tradicionales de la sociedad se observan fuertemente desestabilizados, sumado a una ola inicial de desconfianza y malestar social (PNUD, 2003 y 2012). En este escenario, la sociedad deja de ser una certeza para estos jóvenes; fenómeno que empuja a las nuevas generaciones a proveerse de modo individual dichos sentidos vitales. Las personas renunciarían entonces a «moldear lo social» y se abocarían a moldear sus propias existencias de forma predominantemente individual. Salir adelante sería un asunto de cada quien, reforzándose una suerte de privatización de la felicidad (PUND, 2012). Cuestiones que las industrias del consumo y la expansión del self, han sabido capitalizar eficientemente, mediante toda una red de agentes, relatos, mandatos y mercados, donde lo corporal posee un papel estratégico. Dicha oferta de bienes simbólicos que promueven la autorrealización, el cultivo de sí, etc., no estaría diseñada para cambiar la sociedad, sino para cambiarse y modelarse a sí misma, en un Chile de fuerte impronta neoliberal. En el marco,

\footnotetext{
${ }^{2}$ En este punto nos alineamos con la perspectiva de M. Foucault (2012), donde se asume la subjetivación como la dinámica mediante la cual la subjetividad se toma a sí misma como objeto para dar a su vida una orientación determinada, para autoconfigurarse, «esculpirse» a sí misma.
} 
lo que algunos han llamado la «sociedad del espectáculo» y la industria descentralizada ligada a esta; estaríamos transitando desde una sociedad donde predominó el ser a otra donde predominó el tener; y en la actualidad, a una donde predomina el parecer, esto es, una sociedad donde si no se es visto/a o expuesto/a, se hace difícil de que se exista como tal. Si no se muestra lo que se posee a la vista de otros, entonces poco sirve tener lo que sea (Sibilia, 2009). Lo anterior no estaría exento de tensiones e impugnaciones, cuestión que se puede observar de modo más nítido en cierto componente juvenil y generacional que irrumpe a partir del movimiento estudiantil de los años 2006 y 2011, y el de mujeres estudiantes autoconvocadas de año 2018 en Chile.

\section{LA EXPERIENCIA DE LO CORPORAL EN LAS SOCIEDADES CONTEMPORÁNEAS}

En la obra clásica de Mary Douglas (1991), el cuerpo se considera como un sistema de clasificación primario, mediante el cual se gestionan los conceptos de orden y desorden. Asimismo, Mauss (1973) planteaba que la cultura da forma al cuerpo, describiendo meticulosamente lo que él denominó las técnicas del cuerpo (Mauss, 1985). Por su parte, la sociología de G. Simmel (2001) es considerada pionera en el abordaje de los sentidos y la experiencia sensible de los urbanistas en los circuitos de las metrópolis modernas (Sabido, 2017). Actualmente, las ciencias sociales y las humanidades han influido en la legitimación del cuerpo como campo de estudio en la sociedad contemporánea; el análisis de clase y consumo a través de los trabajos de Baudrillard (1974), Bourdieu (1986) y Featherston (1991). La perspectiva interaccionista de Goffman (1971), donde el lenguaje corporal y el orden de interacción en púbico desempeñan un rol primordial en los escenarios microsociales. Más recientemente, con la irrupción de la cultura del consumo y el espectáculo, destacan los análisis de Baudrillard (1974), Featherston (1991), Le Breton (1995) y Turner (1989, 1994), donde el cuerpo se transforma en mercancía y pasa a ser el medio principal de producción y distribución de la sociedad de consumo (Martínez, 2004; Moreno, 2016). Su mantenimiento, puesta en escena, reparación, reconversión exaltación y/o rejerarquización se convierten en temas estratégicos (Corbin et al., 2006; Soley-Beltran, 2010; Martí y Porzio, 2016) en un mundo donde prolifera la incertidumbre biográfica y estructural.

Las ciencias sociales latinoamericanas han hecho eco de la importancia del cuerpo en tanto que construcción sociohistórica, transformándose en un campo emergente de investigación interdisciplinaria en la región, especialmente en Argentina, México, Brasil, Ecuador y Colombia (Sabido, 2011; Nateras, 2002; Figari y Scribano, 2009; Sibilia, 2009; Goldemberg, 2016; Scribano, Magallanes y Boito, 2013; Lindon, 2012; Finol, 2008; Moscoso, 2011), pero la producción de conocimiento en torno a este tópico aún es insuficiente en nuestro país y se hace determinante para comprender el momento de profundo malestar social e incertidumbre biográfica y estructural por el que atraviesa Chile. De ahí que asumamos al cuerpo como un campo de fricción y de disputa por su significación y sus usos, su construcción y modelación social; y también de reapropiación y resingularización de la vida, un potencial espacio de autonomía y agencia social. Esto último abre toda una compuerta de experiencias y formas socioemocionales de conocimiento inusuales en las ciencias sociales. A. Scribano (2009) sostiene que: 
lo que sabemos del mundo lo sabemos por y a través de nuestros cuerpos (...). En ese «ahí-ahora» se instalan los dispositivos de regulación de las sensaciones, mediante los cuales el mundo social es aprehendido y narrado desde la expropiación que le dio origen a la situación de dominación. Las sensaciones están distribuidas de acuerdo a las formas específicas de capital corporal. El capital corporal son las condiciones de existencia alojadas en el cuerpo del individuo, en el cuerpo subjetivo y en el social. (2009, p. 144).

Por otra parte, la fragmentación y secularización actuales de la sociedad facilitan la mercantilización y la rentabilización del cuerpo y la apariencia física, la «sociedad del look» (Lipovestky, 2000). Verificándose un declive del lugar de trabajo y la creciente importancia de la sensibilidad y el hedonismo originados por el ocio (Featherston, 1991; Lipovesky, 2011). El análisis de Baudrillard (1974) considera que la lógica social del consumo es una lógica de consumo de signos, donde el cuerpo aparece dentro del abanico de los objetos de consumo, y bajo el signo de la liberación sexual, el cuerpo comienza a ser objeto de numerosas inversiones narcisistas, físicas y eróticas. El cuerpo aparece aquí como vehículo de redención, sustituyendo al alma como objeto de salvación. La propaganda y la publicidad se encargan continuamente de recordarnos que tenemos un solo cuerpo y que hay que cuidarlo, reciclarlo activamente, rentabilizarlo, etc., tal como se gestiona una empresa, una marca, en el contexto de la economía política del signo; donde el cuerpo es una forma de capital y un fetiche, es decir, una inversión-emprendimiento inacabada y un signo de prestigio social. Featherstone (1991, 2000) investiga el modo en que se experimenta el cuerpo en el marco de la cultura posmoderna y cómo este se constituye en una suerte de dínamo en los procesos de subjetivación actual (Foucault, 2012), ya que desde inicios del siglo XX se verifica un espectacular aumento en los regímenes de autocuidado, el cuerpo se ha convertido en el centro de un trabajo sobre sí cada vez mayor, a través del ejercicio, la dieta, el maquillaje, la cirugía estética, etc., donde se observa una proliferación de estilos de vida sanos y corporales. El cuidado del cuerpo no haría referencia solo a la salud, sino también a sentirse bien; nuestra felicidad y realización personal, cada vez más, están sujetas al grado en que nuestros cuerpos se ajustan a las normas hegemónicas de salud y belleza (PNUD, 2012; Martínez, 2004). Featherstone (1991) distingue dos tipos de exigencias con respecto al cuerpo: cuerpo interior (innerbody), funcionalmente sano y en forma; y la apariencia (outerbody), el verse bien y proyectar una imagen cuidada. Así, el cuerpo es un signo, un dispositivo de comunicación que es hablado por la cultura hegemónica (Ganter, 2005, 2018; Martínez, 2004).

\section{LO GENERACIONAL COMO CATEGORÍA ENCARNADA}

En relación con la noción de generación, es posible plantear que se desarrolló en Europa a partir de tres momentos históricos, que corresponden a tres marcos sociopolíticos concretos: los años 20, en el período de entreguerras; durante los años 60, la edad de la protesta y el conflicto generacional; fines de los años 90 y el ingreso al siglo XXI, con la aparición de la sociedad red, situación en la que las nuevas generaciones (@; \#) poseen más competencias que las generaciones anteriores para innovar digitalmente en la sociedad (Heller, 1988; 
Balardini, 2005; Salazar, 2002; Leccardi y Feixa, 2011), fenómeno que también se denominó como «ruptura generacional» (Mead, 1970). Para el caso chileno, después de la segunda mitad del siglo XX, aparecen con fuerza distintiva tres generaciones: la del 60, la del 80 y las sucesivas mareas estudiantiles generadas a partir del siglo XXI (Muñoz, 2011; González, 2011; Ganter, 2015, 2017; Santibáñez y Ganter, 2016; Feixa, 2018; Álvarez, 2018), con sus respectivos enlaces generacionales impulsados durante los años 2006, 2011 y 2018, en este último año, en su versión feminista y autoconvocada.

A diferencia de la generación del 68, la generación actual se define por factores cosmopolitas (Leccardi y Feixa, 2011). La generación más joven (o cualquiera de sus facciones) actúa como barómetro de las nuevas tendencias culturales, políticas, económicas, etc. En la actualidad, esto se puede observar de manera más radical en el segmento juvenil, donde la aceleración de las tendencias sociales se deja ver más penetrante en estos componentes de la población, debido a que poseen una inédita capacidad para asimilar, procesar e integrar transversalmente la información y los códigos sociales desanclados que hoy circulan por todo el planeta (Margulis, 2003). Reguillo (2000) habla de «metabolismo acelerado», una condición mediante la cual los y las jóvenes actuales encarnan y reproducen de modo más intenso los patrones discriminatorios de la cultura dominante, como el sexismo, la xenofobia, el clasismo, el culto al cuerpo, el hedonismo, el neonarcisismo, el aparentar y simular lo que no se es, la estetización de la vida cotidiana, etc. Por otra parte, sostiene Reguillo, también reelaboraban activamente e impugnan con la misma fuerza esos patrones de la cultura hegemónica, mediante complejas operaciones cognitivas, socioemocionales, estéticas y simbólicas, de colaboración y denegación de la política oficial, etc. (Reguillo, 2000; Nateras, 2002).

Las generaciones pueden pensarse como instancias socializadoras que contienen —al interior de un espacio-tiempo- una diversidad de vivencias encarnadas en la subjetividad, experimentadas individualmente y compartidas socialmente (Margulis, 2003). Para Urteaga (2012), el cuerpo es uno de los espacios culturales más importantes en la disputa entre adultos y jóvenes, también entre generaciones. El predominio del enfoque biomédico ha sido fundamental en la construcción de una serie de imágenes sociales sobre lo juvenil y lo corporal, que han sido ofertadas a las instituciones como definiciones científicas validadas sobre lo juvenil a lo largo del siglo XX y comienzos del XXI. Pero es en los modos en que las generaciones experiencian su cuerpo, donde se hacen explícitas sus relaciones con el mundo. La experiencia del cuerpo se vive en dos niveles, por un lado, a través de la puesta en escena de prácticas corporales (performativamente) y mediante las imágenes sociales construidas en los escenarios en que los actores interactúan con los otros (Urteaga, 2012). La perspectiva del cuerpo juvenil como territorio cultural revela cómo, a través de una trama institucional creada desde el siglo XIX e imágenes institucionales sobre los jóvenes, las políticas contra el cuerpo juvenil han buscado producir cuerpos subordinados y obedientes, a través de su «cultivo», la higienización físico-mental y el asexuamiento. Lo que resalta la necesidad de ubicar al cuerpo como un elemento clave en la construcción de la presencia y visibilidad juvenil en el siglo XXI y en la agenda de investigación que empuja este conjunto de interacciones y problemáticas (Urteaga, 2011 y 2012).

\section{ESTRATEGIA METODOLÓGICA DEL ESTUDIO}


La opción metodológica se inscribe dentro del denominado enfoque cualitativo de investigación social. En ese marco, se trabajó con el método biográfico (Cornejo, 2008; Sautu, 2005), en tanto enfoque epistémico que privilegió la construcción de un saber a partir del diálogo con diversos mundos juveniles. El enfoque biográfico se sumerge en la experiencia vivida, con el objeto de «capturar» la singularidad de lo social, aprehendiendo al sujeto en el contexto de su propia experiencia vital, de los propios métodos con los cuales construye su realidad. Del mismo modo en que el péndulo se dirige hacia lo singular, el método biográfico exige otro desplazamiento hacia la captura de lo colectivo de un fenómeno estructural (De Gaulejac, 1992). Para lo anterior, se privilegió el relato de vida como técnica fundamental para la coproducción de saberes. Asimismo, se privilegió un diseño emergente de investigación y un muestreo de carácter estructural (Ibáñez, 1989), donde lo predominante para la selección de los casos fue el denominado criterio de pertenencia, mediante procedimiento de «bola de nieve» (Ibáñez, 1989; Ruiz Olabuénaga, 1989).

El análisis se estructuró a partir de la construcción de una narrativa biográfica (múltiple), un esquema cognoscitivo e interpretativo para la comprensión del mundo social de los actores; por lo que se privilegió el propio relato de los y las jóvenes en una especie de episodios unidos por una trama social y experiencial común y colectiva (Pujadas, 2000). Asimismo, nos apoyamos en el programa de procesamiento de datos Altas.Ti, y utilizamos los aportes de la Teoría Fundamentada y el método comparativo constante (Strauss y Corbin, 1998) para la organización, construcción, testeo y validación de categorías generadas y vividas por los diversos mundos juveniles presentes en el estudio.

El trabajo de campo recoge 40 relatos de vida de mujeres y varones jóvenes, entre los años 2015 y 2017, organizados generacionalmente, por un lado, bajo la proximidad con épica de la denominada «revolución pingüina» del año 2006 (25 a 29 años), y con el surgimiento y diversificación progresiva de las nuevas tecnologías de la comunicación; mientras que por el otro, organizados bajo la proximidad con la épica de las revueltas globales del año 2011 (18 a 24 años), la consolidación del proceso de globalización, el cuestionamiento profundo a la democracia representativa, el uso político de las redes sociales, el NO + Lucro. En el esquema que propone Féxia (2018), con más o menos matices para el caso chileno, se traduciría como generación @y generación \#. Enfatizamos aquí que las generaciones responden más a cartografías y mapas simbólicos, donde los actores juveniles inscriben dinámicamente sus experiencias biográficas en el tiempo y el espacio, y no a compartimentos estancos sin vasos comunicantes. Además, los relatos adscriben y obedecen a una gran diversidad de mundos sociales, condiciones sociales de existencia, trayectorias familiares, de estudios y laborales; junto con sus variadas adscripciones identitarias, gustos, consumos, intereses y proyecciones.

En la primera fase del estudio, se exploraron de forma flexible los múltiples modos en que se organizan los significados y las prácticas de lo corporal en una diversidad de perfiles juveniles residentes en el Gran Concepción y el Gran Santiago. El proceso metodológico se llevó a cabo a través de jornadas de trabajo sistemáticas que permitieron al equipo investigador definir de manera colectiva y triangulada las categorías interpretativas y sus propiedades, testeando las similitudes y diferencias de cada relato biográfico con dichas categorías (Strauss y Corbin, 1998). Así, procedimos mediante una codificación abierta, la que buscaba expresar y sintetizar los datos y el fenómeno a través de la forma de concepto, 
permitiendo la visualización cuantitativa del número de citas por código. Luego de esto, fue posible alcanzar una compresión más profunda del texto por medio de la categorización de dichos códigos, agrupándolos según el fenómeno que describían.

En una segunda fase, se organizó el material, los relatos, los usos y significados asociados a la experiencia corporal, mediante la adscripción de dichas vivencias en lo que denominamos mundos juveniles, en tanto ejes y/o metacategorías que condesan los sentidos y los modos en que las juventudes y las dos generaciones observadas refieren y gestionan lo corporal en el Chile actual. Tras esto, se procedió a hacer un refinamiento y diferenciación de las categorías. En esta etapa también se elaboraron conexiones, comparaciones de carácter constante y relaciones entre las distintas categorías, donde se construyeron redes conceptuales (por medio del software ATLAS.ti) a partir del primer análisis, sumado a las reflexiones en conjunto y las apreciaciones hechas por el equipo investigador. Es importante señalar que toda esta etapa fue recursiva, es decir, constantemente se volvía al texto (datos), con el objeto de verificar y descubrir nuevos conceptos, categorías y relaciones. El procedimiento de interpretación e integración de los datos adicionales finalizó cuando se alcanzó la saturación de la información.

En una tercera fase, se procedió a compartir los relatos de vida transcritos y editados a un conjunto de jóvenes participantes del estudio, de modo que incluyeran sus apreciaciones, impresiones e indicaciones, particularmente a la sección de presentación de resultados de este artículo, lo que denominamos corpografías y sus respectivas tipologías. Tensionando, retroalimentando y validando los hallazgos de la investigación. ${ }^{3}$

Todos estos estos elementos constituyen la «cocina» y el soporte para llegar a proponer y construir — inductivamente - un nombre y un marco de referencias para cada una de las tipologías que aquí presentamos. Por razones de espacio, lo que aquí mostramos forma parte de una selección parcial de resultados, vinculados con un primer estrato de mundos juveniles pesquisados, cuyo eje narrativo se sustenta en la experiencia de lo corporal, y que a partir de la evidencia empírica organizamos metodológicamente a través de las siguientes tipologías: i) Cuerpos Decorados; ii) Cuerpos Movidos; iii) Cuerpos en Forma, iv) Cuerpos Modelados; v) Cuerpos Precarizados; vi) Cuerpos Divergentes; vii) Cuerpos AlterCapacitados.

Al interior de cada una de estas siete tipologías se podrá observar: i) un perfil sociocultural y estructural de los jóvenes que aglutina; ii) las significaciones-sentidos que de ellas se desprenden y distinguen; iii) el conjunto de prácticas que comparten y/o repertorio de hábitos que los diferencia. No obstante, el estudio reconoce la gran diversidad y complejidad de los mundos juveniles y los desiguales modos de vivirlos en el Chile actual, por lo cual, dicho modo de organizarlos no constituye para nada un modo clausurado de comprenderlos, y debe entenderse como lo que es: una tipología interpretativa que forma parte de un ejercicio empírico provisorio y abierto a la discusión.

\footnotetext{
${ }^{3}$ Hay que hacer mención que en la fase de cierre del proyecto Fondecyt, durante abril del año 2018, en el marco de la colaboración internacional del mismo, se realizaron un conjunto de talleres y presentaciones con colegas de la Universidad Federal Fluminense de Brasil, Dra. Paula Sibilia, y de la Universidad Autónoma de MéxicoIztapalapa, Dr. Alfredo Nateras, quienes alimentaron analíticamente los resultados del estudio. Vaya un agradecimiento para ellos también.
} 
TABla 1. Muestra DEL ESTUdiO

\begin{tabular}{|c|c|c|c|}
\hline Género & $\begin{array}{c}\text { Segmento } \\
\text { socioeconómico }\end{array}$ & $\begin{array}{l}\text { Edades: entre } 18 \text { y } 29 \\
\text { años }\end{array}$ & $\begin{array}{c}\text { № de casos: Concepción } \\
\text { y Santiago }\end{array}$ \\
\hline \multirow{3}{*}{$\begin{array}{l}\text { Femeni } \\
\text { no }\end{array}$} & \multirow[t]{2}{*}{$\begin{array}{l}\text { Pertenecientes a } \\
\text { grupos medios }\end{array}$} & $\begin{array}{c}25-29 \\
\text { (Generación Pingüina) }\end{array}$ & 9 \\
\hline & & $\begin{array}{c}18-24 \\
\text { (Nativos/as digitales) }\end{array}$ & 5 \\
\hline & $\begin{array}{l}\text { Pertenecientes a } \\
\text { grupos precarizados }\end{array}$ & $\begin{array}{c}25-29 \\
\text { (Generación Pingüina) }\end{array}$ & 11 \\
\hline \multirow{3}{*}{\multicolumn{2}{|c|}{$\begin{array}{l}\text { Masculi } \\
\text { no }\end{array}$}} & & $\begin{array}{r}\text { Subtotal: } 25 \text { relatos de } \\
\text { vida }\end{array}$ \\
\hline & & $\begin{array}{c}25-29 \\
\text { (Generación Pingüina) }\end{array}$ & 8 \\
\hline & & $\begin{array}{c}18-24 \\
\text { (Nativos/as digitales) }\end{array}$ & 3 \\
\hline & $\begin{array}{l}\text { Pertenecientes a } \\
\text { grupos precarizados }\end{array}$ & $\begin{array}{c}25-29 \\
\text { (Generación Pingüina) }\end{array}$ & 4 \\
\hline & & & $\begin{array}{r}\text { Subtotal: } 15 \text { relatos de } \\
\text { vida }\end{array}$ \\
\hline TOTAL & & & 40 CASOS \\
\hline
\end{tabular}




\section{Principales Resultados del estudio}

\section{TIPOLOGÍA 1. CUERPOS DECORADOS: «MI CUERPO ES UN LIENZO EN BLANCO Y YO LO DISEÑO CONTINUA Y CREATIVAMENTE A MI GUSTO»}

\begin{tabular}{|l|}
\hline Ficha perfil sociocultural y estructural Cuerpos Decorados \\
\hline Aspectos socioeconómicos: grupos medios. Aspecto generacional: 18-24 años. \\
Solteros/as. Trayectorias familiares: padres profesionales, residentes en las ciudades de \\
Santiago y Concepción. Estudiaron en colegios particulares y católicos. Trayectorias \\
laborales y profesionales: actualmente estudian carreras vinculadas con las ciencias \\
sociales y el arte. Distribuyen su tiempo entre el trabajo y los estudios. Grado de \\
individuación: la sociedad aparece como un elemento desdibujado en sus vivencias, con \\
un escaso nivel de asociatividad. Poseen un importante nivel de individuación, donde las \\
redes sociales juegan un papel importante en dicha dinámica. Redes de apoyo y \\
socialización: no es posible identificar en el discurso este componente. Visión de futuro: \\
horizonte de futuro marcado por alcanzar una profesión, o bien, por consolidarse en lo \\
que actualmente los ocupa e interesa. Se perciben como optimistas. Las actividades que \\
desarrollan estos jóvenes van desde modificadores corporales, tatuadores, hasta usuarios \\
de las diversas variantes del arte corporal y la modificación corporal en general.
\end{tabular}

Tipología que da cuenta principalmente de la modificación corporal, donde el cuerpo, o mejor dicho la carne, está sujeto a una serie de servicios racionalizados y a la industria de lo corporal y el embellecimiento, aunque no todos/as sus usuarios/as reconocen las prácticas de consumo y producción pasiva frente al mercado. La práctica del tatuaje puede ser interpretada y formar parte de un capital social (Bourieu, 1998) que "produce cuerpos estéticamente mejorados y socialmente reconocidos» (Atkinson, 2016), performando una determinada individualidad gracias a la personalización del cuerpo.

\section{a) Sentidos y significados de lo corporal}

En general el imaginario del cuerpo se asocia con un lienzo, «una hoja en blanco». Cada intervención o práctica decorativa realizada sobre el cuerpo no es azarosa; los tatuajes se hacen en una determinada zona del cuerpo, con colores y diseños específicos, en un claro momento biográfico de los jóvenes: «Una persona se puede tatuar un punto y ese punto, si le da un significado de algo... va a ser súper importante. Porque el tatuaje en sí es algo estético, y es algo cultural, y es algo simbólico» (tatuador, Concepción).

En la mayoría de los casos observados, también es posible constatar que la experiencia socioemocional del tatuarse se asemeja a una especie de adicción, dada la adrenalina y la endorfina que se liberan en estos contextos. Se plantea una convivencia entre imaginarios del arte y la estética con imaginarios donde predomina la mercantilización de esta práctica: «No puedes englobar todas las actividades del tatuaje como un arte porque también es un bien de 
consumo (...) la expresión de arte no la puedes comprar ni vender, ¿cachái? El tatuaje (...) sí lo puedes comprar y vender» (tatuador, Concepción).

Sin embargo, esto no impide que exista una disputa con los imaginarios dominantes acerca de lo corporal y el canon occidental del cuerpo bello: «A muchas niñas nos causó muchos problemas de autoestima (...) entonces, cuando vi que destacaban una belleza diferente, era como genial (...) Veo la belleza de una manera más diferente» (suicide girl, Santiago).

También es posible observar una resignificación de la experiencia del dolor físico: «De hecho, es como un dolor satisfactorio porque es como, lo que pagas por el tatuaje, viene incluido el dolor (...) es fome hacerse un tatuaje y no sentir nada, tener que sentir la experiencia que te están tatuando y sentir el dolor po, cachái» (tatuadora, Concepción).

\section{b) Repertorios, usos y prácticas de lo corporal}

En los casos de quienes desarrollan la modificación corporal como oficio, se manifiesta la existencia de un saber no convencional sobre y desde lo corporal. Un saber sobre anatomía y los procesos ligados a esta, donde destacan los aspectos de la circulación de la sangre, la cicatrización de cortes y heridas en la piel, la prevención de infecciones, los cuidados, la higiene, etc.: «Si te echas algún medicamento puedes sufrir alergia por lo mismo, y si no te echas nada, se cicatriza naturalmente y te queda más bonito» (tatuadora, Concepción). Se evidencia un conjunto de técnicas, procedimientos y métodos propios de este campo de prácticas; además de un conjunto de insumos y herramientas específicos asociados con este mundo: jeringas, máquinas de tatuar, diversos tipos de tintas, instrumentos, etc. No obstante, aun cuando se observan niveles de autonomía importantes respecto de saberes más convencionales, se mantienen puentes fudamentales con el conocimiento biomédico: «Dependiendo de lo que quieras hacer, hay distintas máquinas. Máquinas para línea, máquinas para relleno. Dentro de las máquinas para línea puedes encontrar rotativas o de bobina, que es cómo funciona el golpe que hace la máquina. Lo mismo las máquinas de relleno. Hay máquinas para distintos rangos de línea. Para línea delgada, línea mediana y línea gruesa» (tatuador, Santiago). 
TIPOLOGÍA 2. CUERPOS MOVIDOS: «MI CUERPO ES MOVIMIENTO CREATIVO PARA MI PROPIO DESARROLLO Y DISFRUTE»

Ficha perfil sociocultural y estructural Cuerpos Movidos

Aspectos socioeconómicos: grupos medios. Aspecto generacional: 20-24 años. Solteros/as. Trayectorias familiares: variado; padres profesionales y con estudios de educación secundaria. Estudiaron en colegios particulares, públicos y liceos. La mayoría de estos jóvenes viven con sus padres en las ciudades de Concepción y Santiago. Trayectorias laborales y profesionales: actualmente, la mayoría se encuentra trabajando en el área de la preparación física (tras haber estudiado en centros de formación técnica y profesional), a excepción de una joven que se encuentra estudiando una carrera profesional. Grado de individuación: la sociedad aparece como un elemento desdibujado en sus vivencias, pero cuando aparece se identifica como una zona de malestar yl aunque no predomina una experiencia de asociatividad importante, sí se observa la participación en orgánicas culturales y donde se estructura el tiempo libre. Redes de apoyo y socialización: la mayoría describe la «vida de barrio» como la forma de establecer vínculos y amistades con sus pares durante la infancia, recordándolo como parte importante de sus biografías. Destacan por tener redes de sociabilidad amplia y conocer a mucha gente, sobre la base de la experiencia corporal que desarrollan. Visión de futuro: el horizonte de futuro de estos jóvenes aparece poco definido, pero fundamentalmente porque están más centrados en la vivencia del presente. Destaca su confianza en ellos mismos y la satisfacción con sus vidas. Las actividades que desarrollan estos jóvenes van desde prácticas postdeportivas, como el skate, el parkoure, hasta la bicicultura, la danza, etc.

Tipología que refiere a la conciencia corporal y a la red de conexiones entre los sentidos corporales y procesos kinestésicos que permiten y dotan al cuerpo de una conciencia censomotora expresada en el movimiento (Simmel, 2001; Sabido, 2017), superando el tradicional dualismo cartesiano, el cual asume una separación irreconciliable entre la mente y el cuerpo. En este grupo, dichos componentes de la experiencia vivida no operarían de modo fragmentado, ya que por medio de la kinestésica habría un proceso relacional entre la mente y el cuerpo, desarrollando la capacidad de afectar y ser afectados a la vez (Blackman, 2008). También dentro de este grupo adquiere relevancia el concepto de técnica corporal (Mauss, 1973).

\section{c) Sentidos y significados de lo corporal}

En este grupo de jóvenes se observa una trama de significados que conciben lo corporal como una experiencia integrada y consciente en su vida cotidiana, esto es, una experiencia tangible que se vivencia fundamentalmente mediante el movimiento corporal, cuya gestión incluye la precisión, la coordinación, la ingravidez, el equilibrio. Aquí, lo corporal no se concibe como un elemento accesorio de la vivencia personal, eso es, disociado de la 
subjetividad, sino como un dispositivo de autoconocimiento sensible y ensamblado con la experiencia mental, cognitiva, emocional, etc., que se expresa en el movimiento como acción lúdico-creativa para disfrutar y superarse a sí mismo.

En el caso de la bailarina, los significados y sentidos asociados con la danza y su experiencia corporal se relacionan con el autoconocimiento y la presencia consciente de su corporalidad: «Lo primero es que la danza te hace es conocerte a ti mismo, ni siquiera reconocerte, conocerte,» porque la gente no se conoce a sí misma, la gente no sabe que tiene un cuerpo (bailarina, Concepción).

En algunas de estas experiencias, particularmente las asociadas con el skate, destaca un uso comunicacional del espacio urbano, particularmente de ciertos espacios públicos emblemáticos de la ciudad. Estas prácticas postdeportivas son un pretexto para hacer amigos y tejer redes de sociabilidad, reportando el disfrute con otros en un tiempo de ocio, una sensación de bienestar y un estado emocional asociado con un estar-juntos-sin-más. También una vía para ir desafiándose a realizar nuevas proezas en el espacio urbano: «Los skaters somos felices, esa es mi volá siempre (...) Vengo a patinar y normalmente me encuentro con amigos y siempre sale su pitito por ahí y que no es malo tampoco, porque es algo que te libera después de todo un día de estrés» (skater, Concepción). Para el caso de quienes participan del parkur, se trata de «un canal que facilita el volverse mejor cada día más (...) es una disciplina súper individual. Uno entrena en su propio nivel, en función de su propio cuerpo, de su progreso personal» (traceur, Concepción).

En el caso de la ciclista urbana, la bicicleta constituye más que un medio de transporte, más que un medio que permite ir de un lugar a otro y más que una actividad deportiva. Se trata de un vehículo para atravesar estados socioemocionales y viajar por el tiempo: «Pa’ mí la bici no es como una actividad deportiva (...) la bici es una forma, es un medio para llegar a todo (...) el medio para llegar a la recreación, al goce (...) que te llegue el viento, puedo andar 20 km sin darme cuenta, paseando» (ciclista, Concepción).

\section{d) Repertorios, usos y prácticas de lo corporal}

Los jóvenes que participan de este mundo «saben» cómo moverse, tienen la destreza de moverse de determinada manera, pues manejan un conjunto de técnicas corporales que otras personas no han desarrollado. Se observa un modo de subjetivación donde el cuerpo y la mente no se encuentran disociados como en el común de la gente, es decir, integran mediados por la experiencia corporal del movimiento- los aspectos más racionales con los aspectos físicos y sensomotores. De ahí que a dicho repertorio de técnicas corporales las denominemos inteligencia kinestésica: «El skate es muy psicológico porque si tú lo vei aquí, hay muchos cabros y la capacidad física la tienen (...) pero el desarrollo mental (...) de que tú decí: aquí voy a saltar y voy a caer parao al otro lado; porque la capacidad física de ir y pararse está, pero que la mentalidad te acompañe en eso es súper difícil lograrlo (skater, Concepción).

Se observan métodos relacionales para el ensamblaje del cuerpo y la mente, logando una gestión performática no convencional del cuerpo, aquí destacan técnicas como el lazy o 
el roll:

Cuando uno hace parkour, el objetivo es desplazarse de la manera más rápida y eficaz posible (...) por ejemplo, si se te presentan obstáculos en el camino, una persona normal rodearía esas cosas, ya que no tiene la habilidad suficiente ni la capacidad corporal para sortear esos obstáculos. En cambio, alguien que practica parkour, tiene esas capacidades para moverse. (Traceur, Concepción).

El lazy, es como una técnica básica en donde uno se coloca de costado sobre un obstáculo, por ejemplo, una cerca. Uno apoya la mano del lado del obstáculo, y con la pierna igual del mismo lado del obstáculo, uno hace un péndulo, como balanceando la pierna y saltando hacia el otro lado del obstáculo. En el momento en que uno está en el aire, hace una transición con las manos, saltas hacia el otro lado y cambias la mano para tener control del movimiento (...) El roll es la técnica básica más importante, pero es la más difícil de dominar. Porque requiere como harto control del movimiento, si uno no tiene buen control del movimiento, te puedes fracturar la clavícula. (Traceur, Concepción).

Para la bailarina, también se evidencia un conjunto de técnicas y procedimientos asociados con la movilidad corporal en los espacios cotidianos de la ciudad: «Un control distinto (...) en términos físicos, eso se puede denominar coordinación, capacidad física (...) la bailarina salta el charco así, no lo rodea» (bailarina, Concepción).

\section{TIPOLOGÍA 3. CUERPOS EN FORMA: «YO ENTRENO METÓDICAMENTE MI CUERPO PARA AUTOSUPERARME Y SENTIRME SANO»}

Tipología donde prevalece la idea del cuerpo mecánico, o de una máquina orgánica (Watson, 1970), con conocimientos de medicina, biología y anatomía, que hacen que estos jóvenes gestionen, en general, de modo mecánico su cuerpo, y lo definan desde la eficiencia, la disciplina y el entrenamiento (Synnott, 2016; Foucault 1975). Así como desde la fuerza de voluntad, el rigor, la precisión. El concepto de automonitoreo (Foucault, 1975, 1976) y técnica corporal (Mauss, 1973) son particularmente relevantes dentro de este grupo. 
Ficha perfil sociocultural y estructural Cuerpos en Forma

Aspectos socioeconómicos: grupos medios. Aspecto generacional: 25-29 años. Solteros/as. Trayectorias familiares: diversa; padres de trayectorias vinculadas a actividades empresariales y profesionales. La mayoría estudió en colegios particulares. La mayoría vive fuera del hogar parental, en la ciudad de Concepción y Santiago. No tienen hijos. Trayectorias laborales y profesionales: algunos de ellos cursan estudios de postgrado. Todos trabajan remuneradamente. Grado de individuación: la sociedad aparece como un elemento completamente desdibujado en sus vivencias, hay escaso nivel de asociatividad. Poseen un importante nivel de autocentramiento e individuación, las redes sociales juegan un papel importante en dichas dinámicas. Redes de apoyo y socialización: no es posible identificar en el discurso estos elementos debido, muy probablemente, al alto nivel de observación que hacen de sí mismos. Visión de futuro: más que orientados por metas o sueños de futuro, están fuertemente orientados a los emprendimientos profesionales y laborales que desarrollan actualmente. Son optimistas y se encuentran satisfechos de lo que han logrado, aunque aspiran a alcanzar nuevas metas vinculadas con su desarrollo físico y personal. Las actividades que desarrollan estos jóvenes van desde la físico-cultura, el fitness, el desempeño como personal trainer, hasta la lucha libre como expresión deportiva.

\section{e) Sentidos y significados de lo corporal}

En los relatos de estos jóvenes se encuentran muy internalizados los significados y sentidos del rigor y la disciplina corporal, propios de los procesos de subjetivación generados por la cultura y la industria del fitness; haciéndose evidente tanto en el lenguaje y la retórica con que se expresan, como en sus hábitos, procedimientos y rutinas corporales cotidianas: "Ahora yo peso la comida, entonces si yo saco mi peso, y cada comida tiene que pesar alrededor de doscientos gramos, cada trozo de carne o pollo (...) el deporte exige que tienen que tener esa cantidad de grasa» (fisicoculturista, Santiago). Metáforas y conceptos que hacen alusión al cuerpo como una máquina y a la comida como su combustible: «Digamos que la genética es el tipo de auto (...) si tú te compras un auto normal, a ese auto tú lo puedes hacer correr y puedes hacer que vaya muy fuerte, pero va a tener un límite, que está dentro de lo que son sus capacidades normales» (fisicoculturista, Santiago).

Se evidencia un disciplinamiento, una tecnología aplicada al cuerpo, que es aprendida de acuerdo con lo que dicta un saber experto, donde confluyen la nutrición, la farmacología, la anatomía, la kinesiología y el entrenamiento físico: «El tema de asesoramiento físico, que es en cuanto al entrenamiento, y el tema que es nutricional, que es en cuanto a comida y estilo de vida, y el tema de suplementación y/o farmacología, que son las cosas que se utilizan para ayudarte con las otras dos» (fisicoculturista, Santiago).

Trabajar con y desde el cuerpo, como si se tratara de un laboratorio en el cual se puede experimentar y ensayar nuevos métodos para obtener mayor rendimiento, traspasando el umbral de las propias capacidades para obtener satisfacción personal, donde paradójicamente- la experiencia del dolor físico y la autoexigencia se mezclan con la gratificación emocional: 
Los hombros han sido lo más difícil, pero como lo más gratificante porque es lo que a mí me faltaba (...) en mi categoría, lo que importa es tener forma como de «X» o de «Y", verse como la espalda triangular, cintura pequeña, hombros grandes, entonces, lo que a mí me gusta y más le dedico tiempo es a los hombros y es lo que más me ha costado (...) sí, es gratificante quedar adolorida así (...) ir experimentando con mi propio cuerpo, eso es lo que a mí me gusta más que cualquier cosa, porque por estética, no sé, no a todos les gusta una persona con músculo (...) pero me gusta el ir experimentando, viendo resultados conmigo misma» (físico-cultora, Concepción).

f) Repertorios, usos y prácticas de lo corporal

Las rutinas que ponen en práctica los entrevistados responden a un conjunto de protocolos y movimiento preestablecidos para que el cuerpo alcance la mayor eficiencia posible: «Se inventaron posturas, obviamente la más eficiente, como biomecánicamente, entonces inventaron una postura y ahí tú tienes que hacerlo» (personal trainer, Concepción). El cuerpo es fabricado mediante movimientos estandarizados y de alta precisión: «Todo tiene una simetría, todo tiene una forma, no es nada al azar, entonces, correr a las cuerdas, pegar arriba del ring y todo eso tiene una forma de hacerse» (luchador libre, Concepción).

Es posible hablar de un proceso de racionalización y control de la experiencia corporal: «Dos días antes se corta el agua; tres días antes, los carbos, y el día de la competencia comes azúcar, para que haya como una inyección de azúcar y que tu cuerpo despierte, te inflas y sin agua, para que no haya líquido subcutáneo» (fisicultor, Santiago).

Durante el entrenamiento en contexto de gimnasio, se extrema e intensifica la relación con el cuerpo, llegando a un aislamiento y disociación con el entono, una despersonalización momentánea: «Si bien hacemos todo juntos, nos ponemos los audífonos y nos decimos “ya, no vemos más rato”. Estamos juntos, pero no te pesco, cada uno en su volá» (fisicultor, Santiago). En algunos casos, se trata de llevar el cuerpo al límite de su capacidad física: «Lo que me llama la atención es superar mis límites, como un ciclista que no quiere demostrar que va más rápido, sino que se supera a sí mismo» (fisicocultor, Santiago).

Por su parte, es posible observar una autodisciplina, sobre la base de una organización racional del tiempo, que no solo regula los momentos del entrenamiento físico, sino que organiza el resto de las actividades cotidianas, como la alimentación, en interdependencia con aquello, y dándole estructura al día: «Somos personas con mucho orden, somos muy estructuradas (...) en todos mis ámbitos ha sido un aporte, me ha ayudado a estructurar mi vida, me ha ayudado a ser responsable, ordenado, a tener un carácter» (fisicultor, Santiago).

La dieta también responde a una racionalidad: «Hoy día, me levanté a las siete de la mañana, me comí ocho huevos, con una taza de avena, una taza de granola y media taza de frutos secos (...) a las diez, unas fajitas con una pechuga de pollo envuelta o un bistec de carne con arroz, proteína con carbo» (fisicultor, Santiago). Lo mismo con los fármacos: «Con este deporte está introducido el tema de lo que son los fármacos, totalmente, es parte del desarrollo; de forma natural te puede ir estupendo, pero si quieres llevarlo a un nivel profesional, sí los necesitas» (fisicultor, Santiago). 


\section{TIPOLOGÍA 4. CUERPOS MODELADOS: «YO CULTIVO Y TRABAJO DE MODO CONSTANTE EL VERME BIEN, ME AYUDA A ESTAR MEJOR CONMIGO MISMA/O»}

\section{Ficha perfil sociocultural y estructural Cuerpos Modelados}

Aspectos socioeconómicos: segmentos medios y medios-altos. Aspecto generacional: 18-24 años. Solteros/as. Trayectorias familiares: En general, viven fuera del hogar parental, no tienen hijos y son solteros. Estudiaron en colegios particulares y han tenido la oportunidad de vivir fuera de Chile. Trayectorias laborales y profesionales: se desempeñan (o han desempeñado) profesionalmente y de modo amateur en actividades vinculadas con el mundo del modelaje. Grado de individuación: poseen un importante nivel de individuación, las redes sociales juegan un papel estratégico en dichas dinámicas. Redes de apoyo y socialización: no es posible identificar en el discurso estos elementos. Se puede inferir que la industria del culto al cuerpo (cuidado y belleza) hace desaparecer al otro, siendo además un rubro muy competitivo que no permite generar fuertes vínculos de redes de apoyo y socialización. Visión de futuro: se observan satisfechos con sus trayectorias personales y laborales. Se autoperciben como innovadores/as; cultivan el cuerpo y la salud a partir de una visión que recupere lo natural y lo alternativo. Las actividades que desarrollan estos jóvenes están ligadas fundamentalmente con el modelaje tanto en su versión profesional como en sus expresiones más esporádica.

Tipología asociada al mantenimiento del cuerpo, es decir, a su cuidado y atención para evitar su degradación continua, su descapitalización frente a la amenaza de la gordura y la vejez. Se observa aquí un trabajo sobre el cuerpo externo tal cual se trabaja una materia, donde se lo puede moldear y concebir como proyecto inacabado (Featherstone, 1991). Tipología fuertemente orientada al manejo de impresiones, a la presentación y exhibición del yo en escenarios cara a cara (Hepworth y Featherstone, 1982). Debido a los perfiles de este grupo, también es importante destacar la relevancia de la acumulación de capital físico para convertirlo luego en un capital económico.

\section{g) Sentidos y significados de lo corporal}

En los relatos de estos jóvenes se configura una trama de significados y sentidos sobre y desde lo corporal, que se asocia fuertemente con una concepción que asume al cuerpo como un emprendimiento, una nueva oportunidad de negocio, un yacimiento para ser desarrollado y explotado. Asociado a este hecho social, toda una red de agentes que consideran a la belleza y la apariencia física como parte de una industria muy rentable en nuestras sociedades.

Yo estoy obligada a trabajar con mi imagen y con mi cuerpo cachái, tengo que cuidarme, no puedo darme el lujo, aunque suene súper loco quizás, de, por ejemplo, el Dieciocho comer como vaca, sabiendo que tengo que grabar una hueá de TVN. Tengo que reprimirme, y obviamente igual es 
paja, pero es parte del business, entonces también eso es una diferenciación. (Modelo mujer, Santiago).

Por otra parte, se observa convergencia en los relatos de este grupo que asocian la belleza corporal con referencias constantes a la naturaleza, la pureza, la simplicidad, la espontaneidad, etc.: «Para mí no es bello el exceso de maquillaje, el exceso de accesorios, exceso de pelucas, no sé, no lo encuentro bello, para mí bello es la simpleza, me siento cómodo, me siento pleno, siento que estoy haciendo deporte, siento que estoy comiendo bien, para mí por ahí va la belleza. Estar más liviano en la vida» (modelo varón, Santiago).

Destaca en algunas biografías, preferentemente de mujeres, la presión que ejerce tanto el medio en el cual se encuentran insertas, la industria con la cual interactúan y el peso de los mandatos sociales hegemónicos para alcanzar mayor aceptación social:

Los compañeros de gimnasia me decían «oye, los limones que tení», me hueviaban porque no tenía pechugas po (...) siempre me rodeaba de mujeres bonitas y voluptuosas, eso incentivó en mí que el concepto de mujer era tener unos senos un poco más grandes (...); entonces, para poder trabajar en ese ambiente y que me contrataran, tenía que tener un poco de pechuga. Te dicen «ojalá que tenga tantas medidas»; entonces ya, relleno, zapato alto para cumplir con el estándar que te piden y al final eso me daba dinero (...) Entonces, cuando salí del gimnasio, de la U, dije «ya, me voy hacer un regalo», y me puse pechugas. No me sentía mujer cachái, como que pa’ mí tener senos era ser mujer (...) ahora estoy súper contenta y plena en ese sentido, de cómo construí mi cuerpo. (Modelo mujer, Concepción).

\section{h) Repertorios, usos y prácticas de lo corporal}

Al interior de este mundo, se comparten variados hábitos, tecnologías de embellecimiento y cuidado de sí, donde identificamos procedimientos para la despigmentación de la piel, el peeling mediante microagujas en el rostro, el uso de cremas, el tatuaje, hasta el uso de cirugía platica y estética como método reconstructivo del cuerpo y también del rostro. Destaca una suerte de empeño contra el envejecimiento. Ello se encuentra asociado a un costo y un sacrificio, aunque bien asumido, dado el beneficio que les reporta en cuanto a su imagen personal:

En la cara me hago peelings (...) te entierran agujas en los poros, y te exfolian la cara, y eso te quema toda la primera piel de la cara, y después de dos días tení la cara como nueva (...) yo me la he hecho regularmente. (Modelo mujer, Santiago).

Tengo una manía, me echo caleta de crema, esa hueá según yo es la clave para nunca envejecer (...) esa hueá te da plus pa' las fotos (...) son hueás tan pequeñas, echarte aceite de resino en las pestañas pa’ que te crezcan, y crecen. (Modelo mujer, Santiago).

Yo me tatué la línea de los ojos, la de arriba y la de abajo (...) aquí fue ya arriba y la otra 
sesión abajo, y nunca más tuve que pintarme o sea, a veces, para remarcar (...) se me hinchó un poquito, después vaselina nomás y liso. (;odelo mujer, Concepción).

Bueno, es que hay dos tipos de implantes. Uno es tipo gotita y está el implante redondo. Entonces, el implante redondo se nota y se ve más prominente (...) yo, por ejemplo, opté por el más natural, una forma de gotita. (Modelo mujer, Concepción).

Asimismo, destaca la renuncia y la privación de ciertas prácticas o consumos, asociados con la construcción de un sentido en torno a lo saludable como estilo de vida, es decir, en tanto modo de estar bien y sentirse bien: «Tení que cuidar tu cuerpo, no de forma enfermiza, pero que ponerle freno si estái comiendo mucho, o hacer deporte o tratar de llevar un estilo de vida sano» (modelo mujer, Santiago). «Trato de tomar harta agua (...) el copete, me restrinjo caleta con el copete, onda engordái caleta; después dejé de tomar y bajé caleta de peso, llegué a pesar cuarenta y tres kilos de puro dejar de tomar, porque no comía ni una hueá, jugos de frutas y maní» (modelo mujer, Santiago).

\section{TIPOLOGÍA 5. CUERPOS PRECARIZADOS: «MI CUERPO ES UNA HERRAMIENTA Y SOBREVIVO DÍA A DÍA SIN SABER SI TODO IRÁ MEJOR»}

Esta tipología apunta a lo mencionado por distintos teóricos sobre cómo las condiciones sociales se inscriben en los cuerpos, particularmente la clase y la desigualdad socioeconómica (Mauss, 1973; Boltanski, 1975; Bourdieu, 1998); donde los cuerpos constituyen en sí mismos un mecanismo de distinción y, a la vez, un dispositivo político de exclusión (Bourdieu, 1998). Aquí se trata de cuerpos y experiencia corporales, sin coberturas, expuestos a condiciones de desafuero y sistemáticamente a situaciones de exclusión, violencia, muerte, estigmatización, desarraigo, abandono, hambre, frío, angustia, etc. Aquí la condición material del cuerpo (precario) opera como mediadora simbólica de todas las experiencias biográficas y sociales (Pedraz, 2010). 


\section{Ficha perfil sociocultural y estructural Cuerpos Precarizados}

Aspectos socioeconómicos: grupos precarizados. Aspecto generacional: 25-29 años. Solteros/as. Trayectorias familiares: precariedad laboral y educacional de los padres. Trayectorias marcadas por el quiebre con la familia nuclear, debido a distintas situaciones asociadas con vulneración y abandono. También está presente el consumo de drogas al interior del grupo familiar. Todos/as han estudiado en escuelas municipalizadas y la mayoría no ha completado la enseñanza media. Trayectorias laborales y profesionales: inserción en el mercado de trabajo altamente inestable y precaria, cayendo muchas veces en actividades ilícitas. La subocupación, el desempleo, la rotación laboral y hasta la mendicidad son características del perfil ocupacional de este grupo de jóvenes. Grado de individuación: la sociedad aparece como un elemento completamente desdibujado en sus vivencias, salvo como factor de exclusión y violencia. Hay nulo nivel de asociatividad. Poseen un escaso nivel de individuación, las redes sociales y la tecnología no constituyen un factor importante en las dinámicas de individuación. Redes de apoyo y socialización: se trata de jóvenes en situación de exclusión social, con escasas redes de apoyo, salvo las organizaciones e instituciones (Hogar de Cristo, grupos juveniles religiosos, entre otras) que se han transformado, tácticamente, en soporte material, emocional y espiritual. Visión de futuro: nula o muy difusa proyección o anhelos personales de futuro, con predominio fuerte de la incertidumbre. Este grupo de jóvenes incluye, desde una mujer que desarrolla un empleo precario por las noche en un mall, pasando por una inmigrante que trabaja en el comercio ambulante, hasta una joven trabajadora sexual, una madre adolescente en situación de exclusión, jóvenes con episodios de consumo problemático de pasta base, hasta un joven en situación de calle, etc.

\section{i) Sentidos y significados de lo corporal}

Los relatos de este mundo asocian lo corporal con un artefacto para trabajar; otras veces, un vehículo para desplazarse por la ciudad, un envoltorio, un depósito sobre el cual intervienen saberes y fuerzas ajenas a él. Siempre disociado de una experiencia más subjetiva y emocional. También aparece como el lugar donde se inscribe el dolor, el estigma y la derrota; la zona más expuesta a las violencias del entorno y sus agentes. Las autoagresiones, el consumo de pasta base, el alcohol, las peleas callejeras, la explotación, el abuso, etc. Asimismo, se dibuja como cuerpo-herramienta; cuerpo-instrumento para la sobrevivencia cotidiana.

La forma de utilización es pragmática, la posibilidad de correr por las calles cuando la policía reprime al comercio ambulante: «Para trabajar, para todo en esta vida sirve el cuerpo, si fuera la cabeza no más, no serviría de nada» (mujer inmigrante, Concepción).

Para el caso de la trabajadora sexual se trata de una herramienta de trabajo, para conseguir dinero de forma rápida, aunque inevitablemente asociada al dolor físico y emocional: «Me dolían mis partes, yo dije, esta hueá por la plata nomás, la plata es lo que hacía que se pasara el dolor, es una hueá, pero no sé si mental o física» (trabajadora sexual, Concepción). 
Para el joven en situación de calle, el cuerpo es un medio para deambular por la ciudad y un escudo para sobrevivir, defenderse, aguantar, en todo caso, siempre una materia ajena. «El cuerpo te maltrata, te agota, te cambia la facción de la cara, no soy la misma persona, como se llama, como erai hace un mes atrás o tres meses atrás (...) entonces la abstinencia, cuando te llega, te empieza a consumir toda la sangre, los glóbulos toda esa cuestión que tenís en el cuerpo» (joven en situación de calle, Concepción).

El joven institucionalizado hace referencia al cuerpo como una «carta de presentación», depende de cómo te vistas, la gente te mira de una manera u otra, esto se relaciona con experiencias de discriminación: «Cualquier defecto te miran de otra forma, yo cacho que el cuerpo es esencial, si andái sucio te van a mirarte de una forma, si andái con tatuajes te van a mirarte de otra forma» (joven infractor de ley, Concepción).

\section{j) Repertorios, usos y prácticas de lo corporal}

En relación con el conjunto de prácticas conscientes sobre el cuidado de lo corporal, el primer relato que hace evidente este tipo de prácticas es el de la trabajadora sexual, derivado de las propias exigencias del oficio que desarrolla. Hay un cuidado estético en cuanto debe «verse bien» para sus clientes, lo que implica depilarse, maquillarse, conseguir ropa especial, esto implica un gasto mensual que está considerado dentro de las tarifas que ella cobra por su trabajo: «Depilación de pierna, rebaje, lencería, siempre es diferente» (trabajadora sexual, Concepción). Prácticas asociadas a los aspectos sanitarios de su trabajo: «Todos los meses tú vas, te haces un control, tienes que ir a tomar pastillas y te las tiene que dar, te da condones» (trabajadora sexual, Concepción).

Sobre prácticas de higiene, en el caso del joven en situación de calle, cada cierto tiempo toma baños en lugares públicos. Existen en él hábitos de limpieza corporal, con el propósito de sacarse la suciedad y la humedad a las que está expuesto. Recorre la ciudad en busca de lugares donde pueda asearse: «Sí po, agua, todo eso es lo que a uno le hace falta po, estando en la calle no podís encontrar (...) en el tiempo de verano me iba a bañarme, como se llama, al Parque Ecuador, ahí me iba a bañarme po, porque el agua es limpiecita, la que baja pa' abajo, entonces me compraba unos jabones, me bañaba ahí, entonces, pa' no andar hediondo, porque el cuerpo se te pone hediondo» (joven en situación de calle, Concepción).

También observamos, en su relato, el despliegue de rutinas y tácticas corporales para sortear las inclemencias del clima: «En invierno, como se llama, cuando ya resistís harto frío, igual como un oso polar cuando duerme, en la noche tenís que aguantar el frío nomás po, que yo he pasado fríos tremendos aquí po; no te vai a tirarte aquí al lado de la iglesia pa' abrigarte po, no po, porqué tenís que caminarla, yo la camino cuando siento mucho frío» (joven en situación de calle, Concepción). 
PERTENEZCO A UNA GENERACIÓN (ALTER)GLOBAL DE CAMBIO SOCIAL»

\section{Ficha perfil sociocultural y estructural Cuerpos Divergentes}

Aspectos socioeconómicos: grupos medios. Aspecto generacional: 25-29 años. Solteros/as. Trayectorias familiares: provienen de familias de profesionales con alto capital cultural. En general, no viven con sus padres y residen en las ciudades de Concepción y Santiago. Diversos y heterogéneos en cuanto a su educación primaria y secundaria. Trayectorias laborales y profesionales: la mayoría son profesionales universitarios o han tenido un paso por la universidad. Algunos realizan postgrados, otros trabajan remuneradamente en lo que han estudiado. En general, están satisfechos con la formación académica y su perfil ocupacional actual. Grado de individuación: poseen un alto nivel de individuación, donde las redes sociales juegan un papel central y primordial en dicha dinámica. Redes de apoyo y socialización: la sociedad aparece como un elemento susceptible de modificar mediante la organización ciudadana, particularmente en ámbitos concretos y específicos, como la regulación de la industria alimentaria, la ampliación de los derechos civiles y las libertades individuales, la profundización de la democracia, la expansión de la participación, la equidad de género, los problemas medioambientales y territoriales, etc. Sin ser militantes, la mayoría desarrolla algún tipo de activismo y participa en redes o colectivos político-culturales. Adhesión generacional: se sienten parte de una generación que nació con el internet y que se incubó al fragor del movimiento estudiantil chileno y la indignación global. Desconfían del mundo heredado por sus mayores. Visión de futuro: están informados y aspiran a la democratización del conocimiento en las redes sociales. Aquí se agrupan jóvenes vinculados con el feminismo, la diversidad sexual, la cannabicultura, los activismos alimentarios y medioambientales, el veganismo, la lucha contra el especismo, etc.

En esta tipología encontramos expresiones altamente conscientes de la dimensión política del cuerpo, en general, se trata de diversas expresiones de activismo generacional de nuevo tipo. Indignaciones de diverso cuño, muchas de estas operando simultánea y combinadamente, a modo de rizoma desde lo corporal, el género, la sexualidad, la alimentación, etc. Aquí, las cuestiones de lo corporal y sus constricciones constituyen un frente, no solo para el rechazo, sino para reivindicar procesos de autonomía y vida creativa, sin que esto destile una ética sustantiva o una utopía común. Se trata más bien de heterotopías.

\section{k) Sentidos y significados de lo corporal}

$\mathrm{Al}$ interior de este mundo juvenil aparece el imaginario de un cuerpo como espacio de reivindicación política y ético. La imagen del cuerpo, su vivencia y sus usos, aparece marcada como un espacio de resistencia e impugnación frente a ciertos mandatos sociales, ciertas industrias que lo mercantilizan y ciertas visiones que lo subordinan y domestican: el machismo, la heteronorma, el especismo, la publicidad, etc.: «Porque el lesbianismo pa’ mí 
es una postura política. No es solo una manera de vivir la sexualidad, ni que sea una condición o una opción sexual, como le llaman algunos. Para mí es una postura política. Entonces, también empecé a teorizar en torno a eso, a entender el régimen heteronormativo, cómo se inicia en el cuerpo» (joven feminista, Santiago).

Para el joven activista de la gordura, la lucha constante contra su cuerpo le hacía daño en términos de su salud mental, por lo cual, desde el momento en que comenzó a aceptar su cuerpo tal como es, emprendió una lucha micropolítica: «Mi cuerpo modificó mi postura política (...) el aceptarse como gordo al único que beneficia es a ti, porque veís las cosas de una manera distinta, te relacionaí de manera distinta, estái más contento, más pleno, no tení tantos miedos al hablar, no tení tantas tapaduras, no tení tanto temor a no ser aceptado» (activista de lo gordo, Concepción).

Surge en los relatos la visión de un cuerpo reivindicado, en oposición a un cuerpo que se niega y no se reconoce. Asimismo, se observa un cuerpo que impugna y se autoafirma en el rechazo consciente a ciertos modos convencionales y predominantes de subjetivación corporal, de concebir y vivir lo corporal: «Con el tiempo, ese proceso de aceptación, ese juego, por ejemplo, de erotizarte tú misma con tu propio cuerpo (...) igual una lo nota en la forma de caminar, de vestirse, como de llevarse a sí misma, esa impronta de cómo yo me quiero (...) el cuerpo igual es un tema pa’ mí, como arma también en términos políticos (...) tengo este rollo igual con los binarismo, no me gustan, siempre he pensado fugarme de ese hombre-mujer, bueno-malo, bonito-feo» (joven andrógina, Concepción).

\section{l) Repertorios, usos y prácticas de lo corporal}

La joven feminista plantea que el hábito de cortarse el pelo o vestirse con pantalones fueron formas de expresar su desacato a la organización convencional de la estética femenina, lo que se inició en su etapa escolar. Luego fue adoptando un estilo de forma más consciente: «Yo, en ese minuto, también me corté el pelo, obvio. Que es un hito yo creo para muchas lesbianas, a algunas les carga, pa’ mí tuvo importancia eso, también de posicionarme estéticamente como lesbiana» (joven feminista, Santiago).

En el caso del cannabicultor, la sustancia sería un vehículo que mejora el ánimo y la versatilidad, por lo cual destaca un consumo habitual y ritual, particularmente antes de realizar actividades recreativas y de esparcimiento colectivo:

Fumo en la mañana, sobre todo un sativo, así que te ayuda a despertar un poco, y como llego mucho rato después a la pega, da lo mismo; y en la tarde, cuando salgo, llego a la casa y me pongo, fumo, pero son pequeñas cantidades generalmente (...) hacer la previa antes de ir a un carrete (...) juntarse a echar algo de humo antes de ver una película (...) te ayuda a llegar con una disposición mejor, la mente más abierta, te puede ayudar a concentrarte mejor (...) te permite esa flexibilidad, conexiones en el cerebro, que de alguna forma producto de nuestro estilo de vida, nuestra forma de aprender las cosas, vamos perdiendo esa capacidad que muchas veces tienen los niños, de asociar cosas que los adultos muchas veces no vemos porque estamos metidos en este cuadrado de rectitud (cannabicultor, Concepción).

Otro tipo de hábitos corporales que destaca al interior de este mundo, lo observamos en ciertas prácticas de abstinencia y privación, particularmente las asociadas con el 
especismo y el consumo de alcohol, la gran mayoría, orientadas por concepciones éticas y políticas: «Cuando uno va a cierto lugar, la gente se preocupa de que tú te sintái bien. Entonces, tú les dices: bueno, no como carne, no tomo alcohol, obviamente ellos van a preocuparse (...); mi postura es política, trato de ser consecuente con lo que yo estoy diciendo, de alejarme lo más posible de la rueda del consumo» (joven straight edge, Concepción).

Tipología 7. CUERPOS Alter-CAPACITAdOS: «EsTOY ORGULLOSA/O DE MIS AVANCES COMO PERSONA, MI CUERPO, MÁS QUE UNA LIMITACIÓN, LO SIENTO COMO UNA POSIBILIDAD»

Esta tipología funciona y se constituye a partir de la presencia de otras maneras de comprender, concebir y experimentar lo corporal, sus capacidades y/o eventuales limitaciones o dificultades en diversos ámbitos de la vida cotidiana. Partiendo de lo que se conoce convencionalmente como condición de «discapacidad», o personas con «movilidad reducida», o «diversidad funcional», surgen otras visiones que cuestionan el pensamiento binario que ha predominado en la modernidad occidental, sobre todo en materia corporal y de sensibilidad perceptiva, donde se tienden a privilegiar ciertas capacidades y competencias sobre otras (por ejemplo, ocular-céntricas), tanto a nivel físico como intelectual. Ello, a partir de lo que se conoce como el movimiento de vida independiente, donde no se parte de las limitaciones que poseen las personas, sino del reconocimiento, la autonomía y el potencial humano presente en cada persona, por lo mismo, la posibilidad de concebir «altercapacidades» en el plano físico, emocional, intelectual, etc. Lo anterior implica un reensamble, una nueva articulación que, haciendo referencia a Latour (2004), no tendría que ver exclusivamente con conexiones ocurridas a nivel cerebral, sino que a la experiencia social de desarrollar un cuerpo sensitivo, que, por lo tanto, también requiere un proceso de conciencia corporal, donde las capacidades potenciales - que permanecían latentes - surgen en búsqueda de una articulación con el mundo social, artefactos y técnicas (bastón, silla de ruedas, etc.). 
Ficha perfil sociocultural Cuerpos Alter-Capacitados

Aspectos socioeconómicos: grupos medios. Aspecto generacional: 25-29 años. Solteros/as. Trayectorias familiares: padres y madres no profesionales, algunos con estudios secundarios inconclusos, dedicados a actividades de servicios y construcción. Estudios secundarios en liceos de dichos lugares. Actualmente los entrevistados viven con sus padres. Trayectorias laborales y profesionales: ambos con estudios universitarios en el área de las ciencias sociales. Grado de individuación: nivel de individuación que pugna por logar mayor autonomía, aun cuando la sociedad no constituye un soporte que asegure el éxito de sus proyectos. Redes de apoyo y socialización: fuertes vínculos con los abuelos maternos que destacan como ejemplos de vida y apoyos. También describen lazos de apoyo con sus hermanas/os. No se observan las instituciones, salvo la Teletón. Visión de futuro: variado; algunos poseen un horizonte de futuro de expectativas y proyectos personales, mientras que otros observan con cierta incertidumbre su proyecto de vida debido a su situación física. Aquí se aglutinan jóvenes mujeres y varones que, siendo fundamentalmente estudiantes universitarios, poseen una condición física y/o de movilidad diversa a la mayoría de las personas.

m) Sentidos y significados de lo corporal

En el caso de los relatos de jóvenes que poseen capacidades diferentes al resto de las personas, observamos un sentido crítico respecto de la noción y el paradigma de la discapacidad física, dado que se sienten orgullosos de su autoimagen, de sus propios logros corporales y biográficos; lo anterior, como parte de un largo y poderoso trabajo personal que ellos han realzado consigo mismos. Rechazando actitudes y emociones como la lástima, la aprensión o el exceso de ayuda hacia ellos, dado que constituiría una forma velada de discriminación; y muchas veces limita la gestión autónoma de sí:

Yo nunca me he sentido (...) como disminuido. Nunca sentí que he estado botado por estar en la silla de ruedas (...) la única forma cuando te sientes como discapacitado, es la sobrepreocupación de la gente. Eso es lo que te hace sentir más discapacitado (...) una discriminación indirecta (...) la discapacidad solamente uno se la genera. (Joven con lesión medular, Concepción).

Pero una no es así. Yo me siento muy orgullosa de mí, como la mayoría de la gente soy morena, de piel morena. (Mujer joven no vidente, Concepción).

No obstante, en el caso de la joven no vidente, a pesar de que se evidencia una autoimagen positiva, es posible constatar cómo el contexto social y el imaginario corporal dominante permean su propia relación con la corporalidad, expresada en ciertos mandatos sociales y estereotipos de belleza predominantes, que ejercen mayor encarnación y presión 
en mujeres, cualquiera sea su condición:

Yo creo que nadie tiene una relación sana con su cuerpo, menos ahora (...) que hay una serie de estereotipos sociales que obligan a las mujeres, mientras más chicas, las niñas hacen dieta. Uno tiene que fijarse mucho en el criterio de los otros. Y uno siempre se cuestiona cómo se ve, por lo menos yo constantemente me cuestiono cómo me veo. (...) porque igual hay una cuestión de mandato social, de que uno tiene que ser delgadita, así bonita, media rubiecita si fuese posible. (Mujer joven no vidente, Concepción).

\section{n) Repertorios, usos y prácticas de lo corporal}

En el caso de los jóvenes alter-capacitados, sus relatos tienden a identificar un conjunto de técnicas corporales y psicomotrices; modos particulares de organizar y estructurar la gestualidad, según los escenarios de interacción y los parámetros que imperan en una sociedad «oculocentrista», donde el régimen de la mirada y la visibilidad se impone de modo predominante en diversos contextos de sociabilidad:

Nosotros no gesticulamos mucho con el cuerpo, un poco más con la cara, dependiendo de la emocionalidad (...) a mí me enseñaron a estar así [con la cara de frente], si tú te fijas no es que yo te esté mirando, pero trato a través de seguir tu voz, de tener la cabeza lo más erguida y la espalda lo más erguida posible, para que se parezca lo más posible a que te estoy mirando. (Mujer joven no vidente, Concepción).

En el caso del joven con una lesión en la médula, como parte de su proceso terapéutico, observamos ejercicios de reentrenamiento corporal, donde juega un rol estratégico el reentrenamiento mental, no solo desde el punto de vista actitudinal, sino en operaciones concretas de reensamblaje neuromuscular:

Yo he descubierto que, a través de la reeducación neuromuscular, he logrado mover mi cuerpo. Hacer el movimiento una y otra vez. Tú, al pensar que estás moviendo algo, por ejemplo, te empiezan a mover la pierna, tú no la puedes mover, pero lo piensas, y repites ese ejercicio un día y al siguiente día y así, el cerebro busca entregar la información que tú estás mandando a la pierna (...) Así se va reforzando el impulso. Y eso es lo que ha pasado conmigo (...) si me decían que yo no iba a mover nada; y ahora muevo las dos piernas, me puedo poner de pie. (Joven con lesión medular, Concepción).

\section{DISCUSIÓN DE RESULTADOS Y CONSIDERACIONES FINALES}

En primer lugar, identificamos un conjunto de tendencias, en ningún caso extrapolables a nivel nacional o regional, donde confluyen los relatos de vida de las y los jóvenes. Asimismo, identificamos otro conjunto de hallazgos donde los relatos se prefiguran de modo crítico y divergente respecto del modo más convencional de organizar (y a veces constreñir) la experiencia corporal en el Chile actual, particularmente las que se organizan al interior de las agencias del mercado, sin que por ello dichos relatos lleguen a decantar en una ética más compartida y sustantiva.

Dentro de las tendencias más generales, los relatos de vida aparecen marcados por una 
importante desafección y malestar social, dirigido hacia las instituciones tradicionales (política, Estado, escuela, religión, trabajo, ciudad, etc.); fenómeno que se refuerza con una inclinación a resolver "por sí mismos» las tensiones y precarizaciones que constituyen la vida en el Chile del siglo XXI. Estos resultados coinciden con los hallazgos de los recientes Informes de Desarrollo Humano para Chile (2012), donde, a pesar del evidente descontento social, se plantea que el ser feliz depende más de «uno mismo» que de las coberturas y las oportunidades que la sociedad pueda otorgar («uno se las arregla para ser feliz»). Muchos de los/las jóvenes que participaron en el estudio se abocan, más que a «moldear lo social», a moldear sus propias existencias de forma predominantemente individual, como si se tratara de constantes y sucesivos emprendimientos sobre sí mismos, al interior de una cultura de fuerte impronta neoliberal. Aquí, la experiencia de lo corporal, la apariencia física y el cuidado de sí representan un campo estratégico para el éxito y la integración social (Schilling, 2002). Este dato se expresa de modo más potente en los segmentos medios y en la generación más próximas a los episodios globales y locales vinculados con el año 2011, los llamados nativos digitales. Sin identificar distinciones de género importantes.

En lo específico, y con el objeto de vertebrar la heterogeneidad de los relatos de vida incluidos en el estudio, fue posible identificar dos ejes estructurantes donde se intersectan, en un plano euclidiano, los procesos de subjetivación juvenil (Foucault, 2012) mediados por la experiencia corporal: i) las dinámicas de individuación juvenil (PNUD, 2003), y ii) la presencia, integración y/o rechazo hacia la industria de la imagen corporal y el cuidado de sí (PNUD, 2012). El primer eje lo abordamos desde la dimensión cotidiano-biográfica y las dinámicas de gestión, tensión y cuidado de sí que implica para las juventudes actuales llevar adelante sus proyectos vitales. El segundo, desde los condicionamientos estructurales y oportunidades que disponen actualmente las juventudes para acceder a bienes simbólicos y materiales que la sociedad oferta para proveerse de sentidos vitales y una imagen de sí, en coherencia o disonancia con dichos condicionamientos (ver diagrama 1).

Para el primer eje, fue posible observar cómo se organizaron las tipologías corporales al interior de este plano analítico, donde los segmentos medios aparecen con un importante trabajo de individuación, más acceso a los bienes simbólico-materiales y, por lo mismo, con más recursos para el cuidado y la gestión de sí: cuerpos modelados, cuerpos en forma, cuerpos decorados, cuerpos alter capacitados, cuerpos movidos y cuerpos divergentes. Mientas que los grupos precarizados, cuerpos precarizados, aparecen con serias dificultades y desafueros para acceder a los bienes simbólico-materiales, por lo mismo, con evidentes ausencias institucionales y/o colectivas para generar prácticas de individuación, cuidado y gestión de sí. En coherencia con esa descripción, los horizontes de futuro y proyección de sí son diametralmente opuestos en grupos medios y precarizados; aunque compartiendo la idea de que la felicidad y el logro de las metas personales dependen más de cada uno que de las oportunidades que la sociedad y las instituciones ofrecen.

En cuanto al segundo eje, observamos en los relatos de vida la presencia importante de lo que denominamos como una economía política de la apariencia y el cuidado de sí (Baudrillard, 1974; Goldemberg, 2016; Moscoso, 2011), una forma de gestionar un sector determinado de intercambios de parte del capital (Scribano, 2009). O sea, el modo de producción, distribución y consumo de un cuerpo bello, joven, saludable y en forma, como parte de un proceso biopolítico (Foucault, 2012; Sibilia, 2012); con toda una trama de 
agentes, técnicos, profesionales, expertos, asesores, saberes específicos, espacios, instalaciones, infraestructura, equipamiento, instrumentos, tecnologías, procedimientos, productos, precios y valores de mercado asociados; formas de pago, políticas de marketing y comunicación; una visión y misión corporativas, escuelas de formación técnica, etc. Todo dirigido a la «conducción de la conducta» de poblaciones humanas altamente segmentadas y objeto de sus intervenciones y modelamientos; y donde la población de mujeres aparece como el blanco principal de su captación comunicacional y su constreñimiento simbólico. Lo que el propio informe del PNUD (2012) para Chile reconoce y denomina como una industria de la felicidad y sus respectivos agentes; destacando en el último tiempo un proceso importante de privatización de la felicidad en el Chile actual.

En este nivel analítico se recombinan las tipologías, ya que los grupos medios que más acceso e integración simbólica poseen con lo que denominamos industria de la imagen y el cuidado personal, son los cuerpos modelados, cuerpos en forma y cuerpos decorados; encarnando mandatos, hábitos, itinerarios, tecnologías y rutinas corporales altamente ensamblados con lo que dictan las industrias de la belleza, la moda y el fitness. Mientras que los cuerpos precarizados, cuerpos alter-capacitados, cuerpos movidos y cuerpos divergentes, poseen una escasa integración simbólica con dicha industria, ya sea por rechazo activo (como es el caso de los cuerpos divergentes), o bien, por exclusión estructural de dichos dispositivos de subjetivación (como es el caso de los cuerpos precarizados). 
DIAGRAMA 1. PROCESOS DE SUBJETIVACIÓN JUVENIL MEDIADOS POR LA EXPERIENCIA CORPORAL

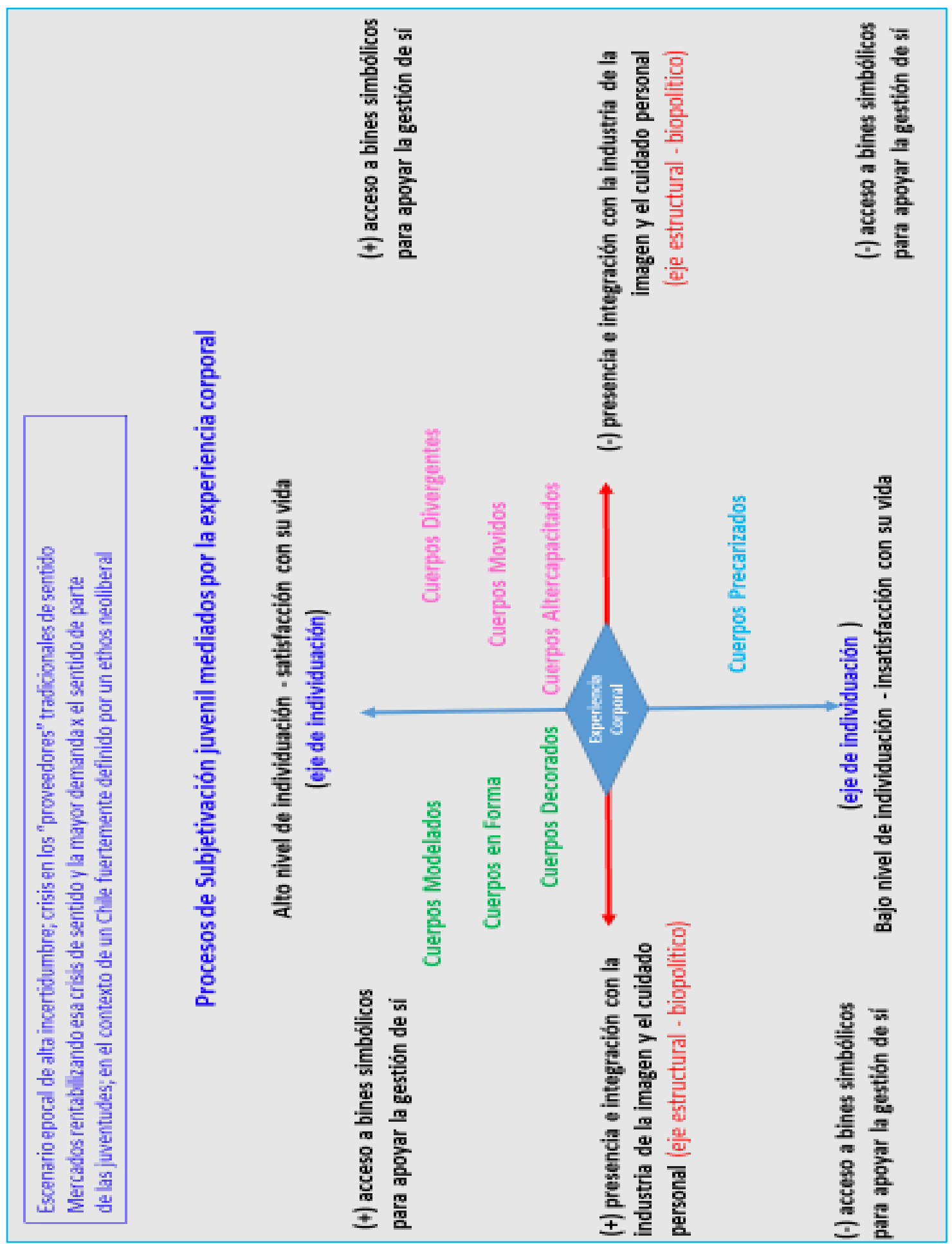

Fuente: elaboración propia.

En cuanto a los imaginarios y concepciones de lo corporal que emergieron a partir de los 
sentidos y significados adscritos a cada tipología corporal, es posible mencionar la identificación de una trama compleja de visiones y concepciones superpuestas, muchas de ellas en interacción y otras en tensión, a la manera de un encadenamiento caleidoscópico de visiones en torno a lo corporal, lo que denominamos, para los efectos del estudio, como corpografía. Para este artículo, desglosamos de modo preliminar los siguientes estratos asociados con dichas visiones de lo corporal:

> Predominio de una concepción biomédica, donde lo corporal se representa como una máquina orientada hacia la eficiencia, muy alineada con visiones cartesianas y binarias (cuerpo-mente) inscritas en los primeros discursos de la modernidad europea. Se alude a un estilo de vida fitness, que combina el ejercicio físico con un estilo de vida saludable. Este imaginario está fuertemente presente al interior de tipologías como cuerpos en forma (Finol, 2008).

> Una concepción donde la salud y la medicina, el poder-saber médico, ya no se inscriben únicamente y exclusivamente en el campo de la medicina convencional o en la intervención de la enfermedad, sino que coloniza y hegemoniza, mediante redes de colaboración con el mercado, los campos de la belleza y la imagen personal. Se trata de la legitimación sanitaria de una estética corporal hegemónica, asociada con la delgadez y la juventud (Moreno, 2016). En ese marco, los imaginarios tradicionales de la salud se recombinan inclusivamente en beneficio de saberes y concepciones cosméticas de la salud, haciendo predominar una visión emocional y capilar del bienestar subjetivo, esto es, el mandato por estar bien, el sentirse bien y el verse bien, el ser positivos, como parte de una nueva arquitectura social vinculada con nuevos procesos de gubernamentalidad, que decantan en una nueva configuración de lo humano (Foucault, 2012). Este imaginario lo introyectan y encarnan de modo más explícito tipologías como cuerpos modelados y cuerpos en forma.

$>$ Auge de una concepción donde del cuerpo, en tanto materia orgánica y biológica, se asume como un proyecto inacabado y en constante manipulación (Giddens, 1991). Para las generaciones actuales, el cuerpo, a diferencia de lo que significó para otras generaciones (la del 60 o la del 80), representa un proyecto modificable, esto es, una materia que se puede modelar, diseñar, tonificar, esculpir, reconstruir, reparar progresivamente, etc. (Le Breton, 1995). Por tanto, muy asociado a un signo, una marca, en el contexto comunicacional de una economía política histórica y geográficamente definida (Baudrillar, 1974; Featherstone, 1991). Este dato se expresa de modo más impotente en las tipologías de cuerpos modelados, cuerpos en forma y cuerpos decorados.

> Se observa la influencia del imaginario publicitario y el de las llamadas industrias de la felicidad, donde predominan estereotipos de salud y pureza corporal: lo blanco, lo delgado, lo liso, lo tonificado, lo juvenil, lo occidental, lo global, privilegiando ciertos 
cuerpos en desmedro de otros (Butler, 2002). Se legitima sociológicamente un estándar de belleza y un cuerpo utópico, que refuerza el éxito y el prestigio sociales (Sibilia, 2012; Golbembreg, 2016; Finol, 2008). En casi todas las tipologías corporales y generacionales observadas, los reatos de vida tienden a converger en una línea narrativa que da cuenta del paso de una época donde predominaron los grandes cambios sociales, a una época donde prevalecen los cambios de uno/a mismo/a; pasando de las utopías políticas y sociales a las utopías corporales. Observamos que el deseo de alcanzar dichos estereotipos puede provocar un alto grado de insatisfacción en la propia imagen corporal, particularmente en mujeres, y desencadenar otros factores como trastornos de la conducta alimentaria, problemas de autoestima e integración social, aspectismo, etc. Este último dato se expresa de modo más impotente en las tipologías de cuerpos modelados, cuerpos en forma y cuerpos decorados.

> Concepción del cuerpo como un capital, es decir, como un recurso integrado a un sistema de equivalencias, un mercado. Se trata de un yacimiento, una empresa, un emprendimiento, en un escenario social de desregulación y predominio neoliberal. Así, el cuerpo requiere un trabajo corporal que se gestiona como un capital (Bourdieu, 1986; Baudrillar, 1974); un capital físico, un capital erótico, sobe el cual se invierte y trabaja intensamente para modelarlo y estar en forma (Schilling, 2002). Aquí, la vejez y la gordura constituirían formas de descapitalización, dado que el canon que rige el sistema dominante de equivalencias legitima la delgadez y la juventud. Si bien es posible reconocer que se trata de un fenómeno extendido en toda la escala social, se expresa de modo más patente en las tipologías de cuerpos modelados y cuerpos en forma; y dentro de ese componente en mujeres jóvenes urbanas, pertenecientes a facciones de la nueva clase media chilena (Sibilia, 2012; Finol, 2008; Goldembreg, 2016).

Visión socioemocional postconvencional del dolor corporal, mediante la cual este transmuta en gratificación, goce y bienestar. Lo anterior supone poner en práctica de modo sostenido un repertorio de hábitos y rutinas corporales que implican sacrificio, esfuerzo, dolor, rigor y disciplina. Tales como: dietas, ejercicios de autosuperación, horas de sueño, tatuajes, aplicación de tecnologías y procedimientos invasivos que requieren rehabilitación, etc. Toda una amplia gama de prácticas de abstinencia, renuncia y privación, con el objeto de obtener un estado corporal ideal, esto es: bello, deseable, saludable, liso, suave, blanco, joven, en forma, tonificado, exitoso, etc. (Scribano, 2009; Sibilia, 2012; Finol, 2008; Goldembreg, 2016). Lo anterior se observa, de modo más visible, en los grupos medios, particularmente en las tipologías de cuerpos modelados, cuerpos en forma, cuerpos decorados, cuerpos movidos y cuerpos divergentes. Y de preferencia en mujeres jóvenes urbanas, sin distinciones en las dos generaciones observadas, quienes viven en mayor medida la violencia simbólica (Bourdieu, 2013) de la normalización de todos aquellos procedimientos, prácticas y hábitos destinados al mantenimiento del cuerpo.

$>$ Una concepción y visión quinestésica de lo corporal, un modo de comprender e 
interactuar con el mundo mediante el movimiento espontáneo, donde el cuerpo no es el vector primordial en la generación del movimiento, sino que es impulsado en y con el movimiento del mundo, se trata de un cuerpo vivido (Merleau-Ponty, 1985). Este dato se expresa de modo más elocuente en la tipología de cuerpos movidos. Es relevante destacar aquí que, al interior de esta tipología de cuerpos movidos, hay una autopercepción más bien latente que tiende a aglutinar los relatos en torno a lo que aquí llamamos épica generacional del año 2011.

> Una visión instrumental y cosificada de lo corporal, donde el cuerpo funciona como una exterioridad, a veces como herramienta, otras veces como escudo para la sobrevivencia, particularmente frente a la sobreexposición del abuso, la violencia, la explotación, el estigma, el clima, el frío, el hambre, etc. (Le Breton, 1995). Este dato lo comparten de modo exclusivo los relatos de jóvenes asociados con la tipología de cuerpos precarizados. Las visiones y condiciones de mayor cosificación se tienden a concentrar aquí en mujeres. Es importante destacar aquí que no hay alusiones a algún tipo de adscripción generacional.

Una visión alternativa de lo corporal a partir del reentrenamiento, uso y despliegue de capacidades diferentes para (re)aprehender el mundo de manera diversa, con una orientación crítica hacia el paradigma de la discapacidad y el predominio de concepciones oculocéntricas en nuestra sociedad (Le Breton, 1995). Este dato lo comparten de modo específico los relatos de jóvenes asociados con la tipología de cuerpos alter-capacitados.

Una visión reivindicativa del espacio corporal, donde lo privado también es político y el cuerpo se concibe y se vive como una agencia (Martí y Porzio, 2016), esto es, como un territorio desde donde pueden detonarse cuidados personales, rechazos y desacatos a una cierta industria y formas de constreñir lo corporal. Aquí, la vida y, consecuentemente, lo corporal, están más próximos a ser concebidos a partir de cambios relacionales y sociales, y también como una obra singular y autónoma; en tanto parte de una ética-estética de la existencia y la libertad (Foucault, 2012). Este dato lo comparten de forma específica los relatos de jóvenes asociados con la tipología de cuerpos divergentes, particularmente en mujeres que se autoperciben como parte de la generación aquí definida como «pingüina». 
DiAGRAMA 2. CORPOGRAFÍA

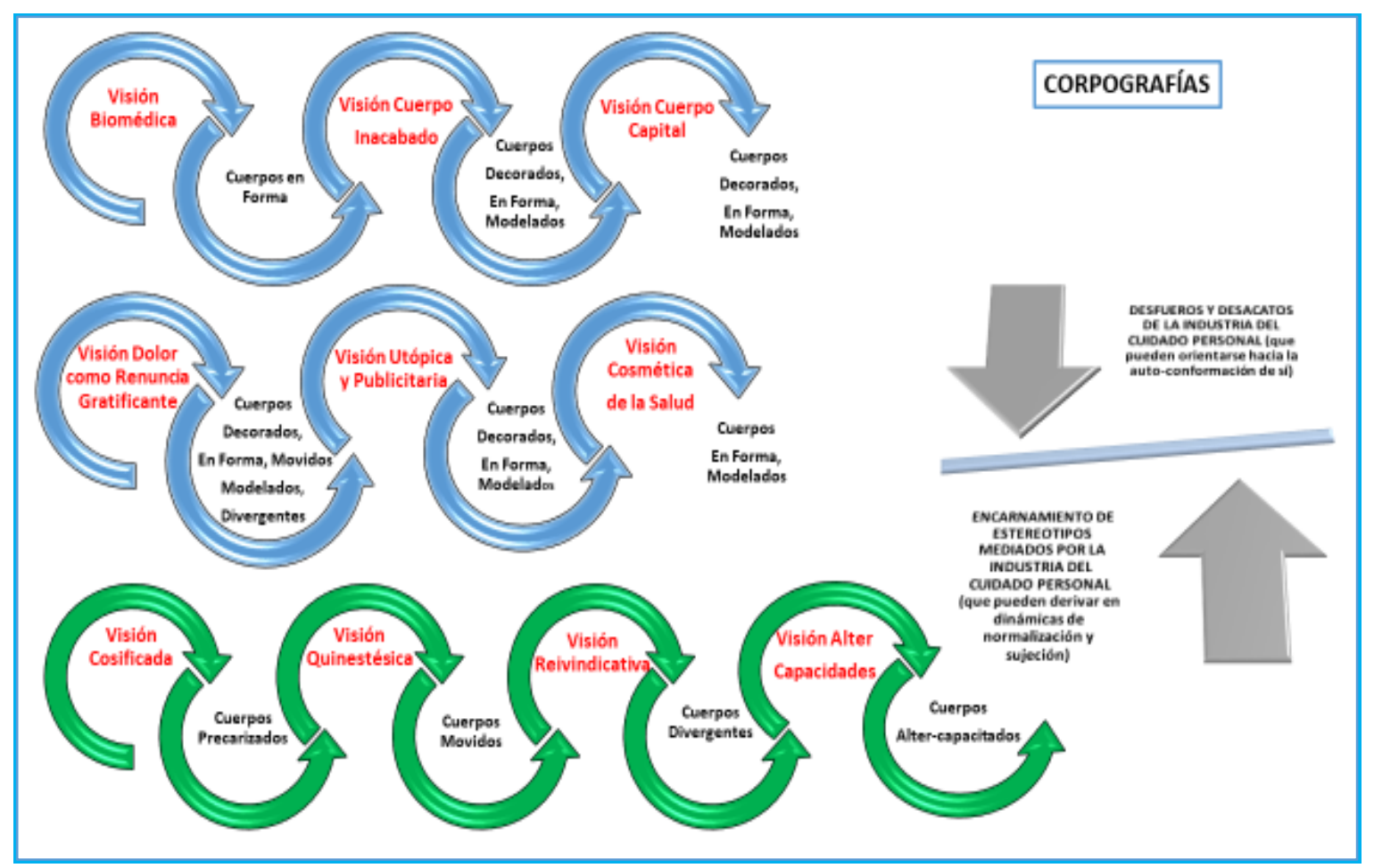

Fuente: elaboración propia.

Asimismo, esta corpografía refleja una paradoja interesante, que además se alinea con hallazgos de otras investigaciones sobre la materia en América Latina; donde, a pesar de la evidente liberalización contemporánea del cuerpo y el deseo, la desregulación del desnudo y su incitación-exhibición de modo profuso en las redes sociales, se ha inaugurado un conjunto de nuevos dispositivos de control y regulación neoliberal sobre la experiencia corporal, más velados y descentralizados (Deleuze, 1991), que reanudan una nueva cruzada —por la vía de la publicidad y el marketing - en torno a los estilos de vida saludables, la estética integral, el culto al self, la alimentación sana, el retorno a lo natural, el deporte y el fitness, etc. (Goldembreg, 2016; Sibilia, 2012)

Todo un nuevo «proceso civilizatorio», donde lo corporal se constituye en un nodo socioemocional, mediante el cual se exige mayor eficiencia, renuncia y rendimiento personal (Crossley, 2004). Proceso civilizatorio que no se encuentra ya en las promesas políticas o ideologías, sino que es impulsado por la nueva moral del «estar en forma», con toda la economía política que la sustenta (definiendo su valor de cambio); y que resulta ser más rentable cuanto más se agudiza el escenario social definido por la crisis de sentido y la ola de incertidumbres que desbordan los contornos del sujeto joven actual (Scribano, 2009; Goldembreg, 2016; Sibilia, 2012; Finol, 2008). Este dato se expresa de modo más importante en las tipologías vinculadas con el cuerpo en forma, cuerpo modelado, cuerpo decorado y 
cuerpo movido; destacando al interior de estas tipologías el segmento de mujeres, sin distinciones importantes respecto de las dos generaciones observadas.

Finalmente, observamos que, muchos vacíos de sentido (PNUD, 2003) presentes en las generaciones actuales ya no logran suplirse mediante las agencias sociales que tradicionalmente los proveían, comenzando a ser llenados — capitalizados — por diversos mercados e industrias (altamente segmentados), que refuerzan la preocupación por el cuerpo y la autoimagen frente a los demás (industria del fitness, de la belleza y el cuidado personal; la moda, la publicidad, etc.). Anteriormente, la confianza y fe se depositaron en la religión, luego en la ciencia; hoy, encuentra su sostén en las industrias del cuerpo, para suplir y reducir — siempre de modo relativo — la preminencia de la incertidumbre (Ferrer, 2006).

Este último dato se expresa de modo más importante en los segmentos medios de ambas generaciones y de modo muy especial, en el componente de mujeres. Precisamente en este último componente, la fuerza de los estereotipos y la presión de los mandatos culturales en torno al cuerpo bello, joven, saludable y en forma se encarnan de modo más intensificado en la experiencia cotidiana de las jóvenes, incluso más allá de su condición de clase, generacional o de «discapacidad» visual. Estos mandatos culturales muchas veces ponen en riesgo el equilibrio socioemocional de las personas; también tienden a acentuar el aspectismo y las desigualdades estructurales prexistentes entre grupos sociales diversos, hecho que se hace más patente en las nuevas generaciones. En relación con lo último, estos mandatos, expresados bajo la forma de violencia simbólica (Bourdieu, 2013), imponen sentidos como legítimos y ubican a las personas en desiguales posiciones sociales, dependiendo de la cantidad de capital acumulado; capital físico en este caso que, si consideramos la variable género, violenta en mayor medida a las mujeres. Esta tendencia se hace más crónica en un contexto social de alta incertidumbre, donde predomina un clima de desconfianza hacia las instituciones sociales y hacia los demás, como es el caso chileno (PNUD, 2012). Lo que, eventualmente, refuerza un repliegue hacia uno mismo, acentuando los procesos de individuación y las propias exigencias sobre la autoimagen: el estar bien, el sentirse bien, el verse bien, el mostrarse bien, el ser positivo/a, etc.

Más allá de la tendencia anterior, también es posible observar dinámicas de subjetivación asociadas con éticas divergentes y corrientes estéticas alternativas y colaborativas, de donde se desprenden prácticas de libertad y de autonomía corporal respecto de las actuales constricciones, normalizaciones y gestiones de la existencia (Estado, industria, patriarcado, mercado, consumo, educación, trabajo, endeudamiento, redes sociales, etc.); muchas de las cuales derivan en procesos experimentales de construcción y diseño de sí que incluyen al «otro/a» generacional; rechazando activamente la deriva individualista y el descuido de sí al interior de las redes del mercado.

A este tipo de experiencias de subjetivación, Foucault (2012) las denomina «tecnologías del yo», es decir, vivencias que en ciertos momentos no responden a formas de sujeción o a tecnologías de poder, sino que se trata de experiencias impugnatorias descentralizadas, mediante las cuales uno se ocupa de sí mismo, se cuida a sí mismo/a, se autoesculpe a través de operaciones concretas sobre su cuerpo, su psiquis, sus pensamientos y sus emociones, reelaborando sus propios hábitos y rutinas, para producir en sí mismo/a una trasformación con claros signos de autonomía. Lo que implica, necesariamente, tensiones y 
antagonismos con las tecnologías de poder, los dispositivos de sujeción, la industria narcisista del cuidado de sí y el cultivo de la imagen personal, su racionalidad, sus estereotipos y los estilos de vida que esta promueve y demanda de modo difuso.

Este particular modo de relación con uno mismo/a, que se evidencia en ciertos relatos de vida levantados por el estudio durante los años 2016 y 2017, prefigura una ética del cuidado de la libertad y la autonomía (Foucault, 2012) y, por lo mismo, una disputa de carácter (macro y micro) político; que no solo implica el rechazo a la racionalidad neoliberal, la industria o a la heteronormatividad, sino que pone en el corazón de su experiencia un agenciamiento colectivo y creativo desde el punto de vista generacional, donde las redes y círculos colaborativos, el poder de la autoconvocatoria y la coparticipación cumplen un papel primordial al interior de las diversas esferas y espacios de encuentro, permeándolos con una fuerte impronta generacional. Aspectos que pudimos observar, de modo más consistente, al interior de tipologías corporales asociadas con cuerpos divergentes; y de modo más latente, en cuerpos movidos. Se trata de lo que, junto con la literatura sobre la materia podríamos plantear como conciencia generacional, esto es, la capacidad de los sujetos de situarse históricamente, en relación con generaciones previas y futuras, junto con la coelaboración intersubjetiva y subjetiva de estos procesos (Leccardi y Feixa, 2011; Muñoz, 2011; Feixa, 2018; Álvarez, 2018).

Una de las hipótesis provisoras respecto de este hallazgo estaría fuertemente asociada con la llamada «revolución pingüina» y sus enlaces generacionales en el Chile del año 2006 y 2011, pero de modo muy particular y directo con lo acontecido durante la llamada «marea feminista» del año 2018 en las universidades de nuestro país; cuya narrativa, orgánica autoconvocante y repertorios performativos de acción/interacción colectiva convergen fuertemente con los repertorios e imaginarios asociados con la tipología de cuerpos divergentes, que fuimos identificando en el contexto del estudio durante los años 2016 y 2017. Cuestionando la corriente identificada por el PNUD (2012) de abocarse a cambios individuales y personales, en lugar de empujar transformaciones más sociales y estructurales.

Resulta conveniente recordar aquí que, este movimiento de mujeres-jóvenesestudiantes del año 2018 partió denunciando situaciones de abuso y hostigamiento sexual, muchas de ellas acumuladas de modo sistemático durante años, en diversos espacios universitarios, escolares y sociales, organizándose de modo autónomo y transterritorialmente, más allá de cualquier partido político, y cuya agenda generacional se orientó a promover una cultura y una educación no sexista y antipatriarcal para el Chile del siglo XXI. Reensamblando relatos, memorias, épicas y experiencias de otras generaciones de mujeres rebeldes del siglo XX en Chile, cuando también se reivindicó lo privado como político; con el objeto de desbaratar estereotipos corporales y de género hegemónicos que están operando de modo naturalizado en nuestra sociedad; terminar con las asimetrías y desigualdades en los modos de relacionarnos y participar en la vida social; regular situaciones de acoso y hostigamiento sexual en diversos escenarios sociales, sobre todo frente a la ausencia de una institucionalidad sobre la materia.

En este caso, las redes sociales, el internet en interacción con la calle, han sido un condensador y catalizador para la expresión viral y generacional de testimonios de mujeres (Feixa, 2018), la generación de vínculos afectivos, la autoafirmación, la contención en círculos de mujeres; la visibilización y el reconocimiento social referido a la magnitud de las 
situaciones vejatorias y coercitivas contra mujeres. Esto también se asocia con lo que autoras como Rossana Reguillo (2017) vienen definiendo recientemente como la construcción de «paisajes insurrectos», de parte de una red heterogénea e interconectada de activistas translocales.

De ahí que la historiadora chilena María Angélica Illanes plantee que:

La aproximación a la cultura y mentalidad de una sociedad y de una época desde la categoría cuerpo, abre (...) importantes perspectivas para su comprensión, desentrañando una de las hebras de su configuración histórica. La categoría cuerpo ha constituido una clave a partir de la cual se han modelado ideológicamente sociedades en los tiempos del mito, de la razón y la religión, sirviendo tanto de arquetipo de comprensión del mundo, como fundamento cognitivo para el ordenamiento jerárquico de la sociedad. Por otra parte, el cuerpo constituye una técnica de poder, tanto como instrumento de conquista y dominación como de rebelión y emancipación. (Illanes, 2002, p. 57).

Finalmente, lo que queremos relevar aquí es la pertinencia y el desafío que supone, para los enfoques interdisciplinarios actuales y el campo de los estudios en juventud, el hacer converger la categoría de cuerpo junto con la categoría de género, generación y estilos juveniles para leer — relacionalmente - el Chile reciente, para comprender sus principales transformaciones, desigualdades y asimetrías, en el supuesto de que las nuevas generaciones, sus imaginarios y prácticas performativas constituyen un barómetro importante para observar los vertiginosos cambios epocales. Queda pendiente para futuros estudios un análisis sobre cuerpo y emociones que ponga a conversar a generaciones «incubadas» en momentos históricos diversos, por ejemplo, los 60, los 80 y el siglo XXI en Chile.

En el caso de este artículo, se ha realizado un esfuerzo preliminar para ensamblar analíticamente varios niveles, en uno más transversal: el neoliberalismo, más que como expresión estrictamente económica, como ethos cultural que define el Chile actual; en un nivel más estructural: lo que el PNUD (2012) plantea como industria de la felicidad y su red de agentes, visiones, mandatos, mercados y tecnologías biopolíticas; en un nivel más intermedio, si se quiere como mediación: lo generacional (barómetro) y sus diversos modos de subjetivación corporal, sus imaginarios corporales, los diversos modos de gestión de sí, donde lo corporal —en la actualidad — opera como un ecualizador de fuerzas internas y externas, un campo en disputa entre la industria y las autonomías juveniles, un campo donde se friccionan generaciones, adultos y jóvenes (Urteaga, 2012); y en un nivel micro: las interacciones cotidianas, tácticas, rutinas y procedimientos «capilares» que adoptan y recrean - como agencia - las juventudes, en el marco de su experiencia corporal concreta, para construir nuevos sentidos y orientar su lugar en un mundo complejo, definido por la incertidumbre, o bien, como lo ha propuesto recientemente la propia Rossana Reguillo para el caso latinoamericano: se trata de acompañar los procesos de estas nuevas generaciones que nos evocan «jinetes en medio de la tormenta».

RECIBIDO: 5 DE MARZO DE 2018

ACEPTADO: 9 DE DICIEMBRE DE 2018 


\section{REFERENCIAS BIBLIOGRÁFICAS}

ÁLVAREZ, C. (2018). La perspectiva generacional en los estudios de juventud: enfoques, diálogos y desafíos. Última Década, 50.

AtKinson, M. (2016). Tattooning and Civilizing Processes: Bpdy Modification as SefControl. En C. MALACRIDA y J. Low (Eds.), Sociology of the body: a reader (pp. 328-335). Oxford: Oxford University Press.

BAUDRILLARD, J. (1974). La sociedad de consumo. Barcelona: Plaza y Janés.

BALARDINI, S. (2005). ¿Qué hay de nuevo, viejo? Una mirada sobre los cambios en la participación política juvenil. Nueva Sociedad, 200, 96-107.

BouRdieu, P. (1986). Notas provisionales sobre la percepción social del cuerpo. En J. VARela (Ed.), Materiales de sociología crítica. Madrid: La Piqueta.

(2013). La dominación masculina. Barcelona: Anagrama.

(1998). La distinción. Criterios y bases sociales del gusto. Buenos Aires: Taurus.

Blackman, L. (2008). The Body: The Key Concepts (Primera ed.). Nueva York: Berg.

Boltanski, L. (1975). Los usos sociales del cuerpo. Buenos Aires: Periferia.

BUtLer, J. (2002). Cuerpos que importan. Sobre los límites materiales y discursivos del «sexo». Buenos Aires: Paidós.

Corbin A., Courtine J. J. y Vigarello, G. (2006). Historia del cuerpo. Volumen III: Las mutaciones de la mirada. El siglo XX. Madrid: Editorial Taurus.

Crossley, N. (2004). Fatis a Sociological Issue: Obesity in Late Modern, Body Conscious Societies. Health and Social Theory, 2(3): 222-253. Recuperado de: https://www.researchgate.net/publication/233699570_Fat_Is_a_Sociological_Issue_Obesit y_Rates_in_Late_Modern_\%27Body-Conscious\%27_Societies

Douglas, M. (1991). Pureza y peligro: análisis de los conceptos de contaminación y tabú. Madrid: Siglo XXI.

DeleuZe, G. (1991). Posdata sobre las sociedades de control. En CH. FerRer (Comp.), El lenguaje literario. Montevideo: Nordan.

Featherstone, M. (1991). The body in Consumer Culture. En M. Featherstone, M. HEPWORTH y B. TURNER (Eds.), The Body: social process and cultural theory (pp. 71-194). Londres: Sages.

Featherstone, M. (2000). Cultura de consumo y postmodernismo. Buenos Aires: Amorrortu. 
FeIXA, C. (1998). De jóvenes, bandas y tribus. Barcelona: Ariel.

(2018). Culturas juveniles como perspectiva para analizar juventudes (1993-2018). Última Década, 50.

FERRER, C. (2006). La curva pornográfica. La Rioja: Pepitas de Calabaza.

Figari, C. y SCRIBANo A. (2009). Cuerpo(s), Subjetividad(es) y Conflicto(s). Hacia una sociología de los cuerpos y las emociones desde Latinoamérica. Buenos Aires: Fundación Centro de Integración, Comunicación, Cultura y Sociedad-CICCUS, CLACSO.

FinOL J. E. y FinOL, D. (2008). Discurso, Isotopía y Neo-Narcisismo: Contribución a una Semiótica del Cuerpo. TELOS. Revista de Estudios Interdisciplinarios en Ciencias Sociales, 10(3).

FouCAULT, M. (1987). Historia de la sexualidad. México: Siglo XXI.

(2012). Tecnologías del yo. Barcelona: Paidós Ibérica.

(1975). Discipline and Punish: The Birth of the Prison. Londres: Penguins Book.

(1976). Society must be defended: lectures at the Collège de France. Londres: Penguin.

GANTER R. (2006). De cuerpos, tatuajes y culturas juveniles. Espacio Abierto, Cuaderno Venezolano de Sociología 14, 1.

(2005). Cuerpos suspendidos: Cartografías e imaginarios de la piel en jóvenes urbanos chilenos. Revista Polis, 4, 11.

(2015). Consumo cultural juvenil: apuntes y pistas para posibles líneas de investigación en el Chile actual. En P. CотTET, Juventudes: metáforas del Chile contemporáneo. Santiago: RIL editores.

Ganter, R., Fuica, I. y Vergara, C. (2017). Caleidoscópolis: signos de cambio en los repertorios de protesta callejera en Concepción. Universum. Talca: Editorial Universidad de Talca.

Ganter Solís, R. y Mendoza, C. (2018). Tecnologías digitales e imagen corporal en jóvenes chilenos de segmentos medios: un estudio de caso mediante ciberetnografía. Revista Latinoamericana de Comunicación, Chasqui, 137.

GidDens, A. (1991). Modernity and Self-Identity: Self and Society in The Late Modern Age. United Kingdom: PolityPress.

GoldemberG, M. (2016). El cuerpo como capital en la cultura brasileña. Perspectivas, 2.

Goffman, E. (1971). Ritual de la interacción. Buenos Aires: Tiempo Contemporáneo.

GOFFMAN, E. (1981). La presentación de la persona en la vida cotidiana. Buenos Aires: Amorrortu. 
Goffman, E. (2006). Estigma: la identidad deteriorada. Buenos Aires: Amorrortu.

GonZÁlez, Y. (2011). Primeras culturas juveniles en Chile: Pánico, malones, pololeo y matiné. Atenea, 503, 11-38. Recuperado de: http://www.scielo.cl/scielo.php?script=sci_arttextypid=S071804622011000100002ylng=es ynrm=iso, consultado: 25/07/2015. http://dx.doi.org/10.4067/S0718-04622011000100002.

HeLler, A. (1988). Los movimientos culturales como vehículo de cambio. Nueva Sociedad, 96.

Hepworth, M. y Featherstone, M. (1982). Surviving Middle Age. Oxford: Basil Blackwell.

IBÁÑEZ, J. y GARCÍA FERRANDO, M. (1989). Cómo se realiza una investigación mediante grupos de discusión. En F. Alvira, J. IBÁÑEz y M. García FERrAndo, El análisis de la realidad social. Métodos y técnicas de investigación. Madrid: Alianza Editorial.

ILlAnES, M. A. (2002). La batalla de la memoria. Santiago: Planeta/Ariel.

INJUV-PNUD (2003). Transformaciones culturales e identidad juvenil en Chile. Santiago de Chile.

LAtour, B. (2004). How to Talk About the Body? The Normative Dimension of Science Studies. Body and Society, 10(2-3), 205-229.

Le Breton, D. (1995). La sociología del cuerpo. Buenos Aires: Nueva Visión.

LECCARDI, C. y FEIXA, C. (2011). El concepto de generación en las teorías sobre juventud. Última Década, 34.

LINDON, A. (2012). Corporalidades, emociones y espacialidades: hacia un renovado betweenness. RBSE, Revista Brasileira de Sociologia da Emoção, 11(33) 698-723.

Lipovetsky, G. (2000). La era del vacío. Barcelona: Anagrama.

(2011). La felicidad paradójica. Barcelona: Anagrama.

Marcús, J., Zicavo, E., Cyunel, V., Felice, M., Schiavoni, B. y UrRoz, M. (2011). Modelos actuales de belleza: la experiencia del cuerpo en las mujeres de diferentes generaciones. VI Jornadas de Jóvenes Investigadores. Instituto de Investigaciones Gino Germani, Facultad de Ciencias Sociales, Universidad de Buenos Aires, Buenos Aires.

Margulis, M. (2003). Juventud, Cultura, Sexualidad: la dimensión cultural en la afectividad y la sexualidad de los jóvenes de Buenos Aires. Buenos Aires: Biblos.

MArtí, J. y Porzio, L. (2016). Cuerpos y agencia en la arena social. Barcelona: Consejo Superior de Investigaciones Científicas.

Martínez, A. (2004). La construcción social del cuerpo en las sociedades contemporáneas. Papers, 73. 
MAuss, M. (1985). Fenomenología de la percepción. Barcelona: Planeta.

MEAD, M. (1970). Cultura y compromiso. Estudio sobre la ruptura generacional. Barcelona: Gedisa.

Merleau-Ponty, M. (1985). Fenomenología de la percepción. Barcelona: Planeta.

Moreno, J. L. (2016). La cara oscura del capital erótico. Capitalzación del cuerpo y trastornos alimenticios. Madrid: Akal.

Moscoso, J. (2011). Reinventando cuerpos. Construcción de estereotipos de belleza a partir del «peso ideal». Quito: Ediciones Abya-Yala/FLACSO.

MuÑOz, V. (2011). Juventud y política en Chile: hacia un enfoque generacional. Última Década, 35.

NATERAS, A. (2002). Metal y tinta en piel, la alteración y decoración corporal: perforaciones y tatuajes en jóvenes urbanos. En Jóvenes, culturas e identidades urbanas. México: UAMPorrúa.

Programa de las Naciones Unidas para el Desarrollo (PNUD) (2012). Desarrollo Humano en Chile, Bienestar subjetivo: el desafío de repensar el desarrollo. Santiago de Chile.

(2002). Nosotros los chilenos: un desafío cultual. Santiago de Chile.

Reguillo, R. (2000). Emergencias de culturas juveniles. Estrategias del desencanto. Bogotá: Norma.

(2017). Paisajes insurrectos. Jóvenes, redes y revueltas en el otoño civilizatorio. Barcelona: Nuevos Emprendimientos Editoriales.

SABIDO, O. (2011). El cuerpo y la afectividad como objetos de estudio en América Latina: intereses temáticos y proceso de institucionalización reciente. Revista Sociológica, 26, 74.

(2017). Georg Simmel y los sentidos: una sociología relacional de la percepción. Revista Mexicana de Sociología, 79(2).

Salazar, G. (2002). Historia Contemporánea de Chile. Tomo V: Niñez y Juventud. Santiago: LOM Ediciones.

SANTiBÁÑEZ, P. y GANTER, R. (2016). Representaciones sociales de lo político: Convergencias y divergencias del relato generacional en el gran Concepción. Última Década, 24(44), 39-70.

SCHILling, C. (2002). Thebody and difference. En K. WoODWARD (Ed.), Indentity and difference. Londres: SAGE Publications.

SibiliA, P. (2009). La intimidad como espectáculo. Buenos Aires: Fondo de Cultura Económica. 
(2012). El cuerpo viejo como una imagen con fallas: la moral de la piel lisa y la censura mediática de la vejez. Comunicação, mídia e consumo, 9, 9(26).

Simmel, G. (2001). El individuo y la libertad. Ensayos de crítica de la cultura. Barcelona: Península.

Soley-Beltran, P. (2010). Cuerpos ideales. Una aproximación interdisciplinaria al estudio de las modelos de moda. Quaderns D’ Arquitectura I Urbanisme, 26, 107-134.

Turner, B. (1989). El cuerpo y la sociedad. México: Fondo de Cultura Económica.

(1994). Avances recientes en la teoría del cuerpo. Revista Española de Investigaciones Sociológicas, 68.

Urteaga Castro Pozo, M. y SÁenz, M. (2012). Juventudes, géneros y sexos. Resituando categorías. Revista del Centro de Investigación. Universidad La Salle, 10(37), 5-21.

URTEAGA, M. (2011). La construcción juvenil de la realidad. Jóvenes mexicanos contemporáneos. México: UAM.

WAtson, J. (1970). Behaviorism. Toronto: W. W. Norton y Company.

\section{BIBLIOGRAFÍA COMPONENTE METODOLÓGICO}

CoRnejo, M., MEndozA, F. y RojAs, R. (2008). La investigación con relatos de vida: pistas y opciones del diseño metodológico. Revista Psykhe, 17(1).

DÁVILA, A. (1995). Las perspectivas metodológicas cualitativas y cuantitativas en ciencias sociales: debate teórico e implicaciones praxeológicas. En J. M. DELGADO y J. GuTIÉRREZ (Coords.), Métodos y técnicas cualitativas de investigación en ciencias sociales. Madrid: Síntesis.

De Gaulejac (1992). Sociologie et psychanalyse des récits de vie: contradictions et complémentarité. En Rencontre Internationale. L'histoire de vie au risque de la recherche, de la formation et de la thérapie. Vaucresson.

Delgado J. M. y GuTiÉRREz, J. (1995). Métodos y técnica cualitativas de investigación en ciencias sociales. Madrid: Síntesis.

PujadAs, J. (2000). El método biográfico y los géneros de la memoria. Revista de Antropología Social, 9.

Rodríguez, G., GIL, J. y GARCíA, E. (1996). Metodología de investigación cualitativa. Málaga: Aljibe.

Ruiz Olabuenaga, J. e IspizúA, M. A. (1989). La descodificación de la vida cotidiana. Métodos de investigación cualitativa. Bilbao: Universidad de Deusto.

SASTRE, A. (2011). Cuerpos que narran: la práctica del tatuaje y el proceso de subjetivación. Diversitas: Perspectivas en Psicología, 7(1), 179-191.

SAutu, R. (2005). El Método Biográfico. La reconstrucción de la sociedad a partir del testimonio de los actores. Buenos Aires: Lumiere.

STRAuSS, A. y CORBIN, J. (1998). Basics of qualitative research: Techniques and procedures for developing grounded theory. Thousand Oaks, CA: Sage. 